\title{
The Role of Individual Surface Flux Components in the Passive and Active Ocean Heat Uptake
}

\author{
Oluwayemi A. GARUBA AND BARry A. KLINGER ${ }^{\mathrm{a}}$ \\ Pacific Northwest National Laboratory, Richland, Washington
}

(Manuscript received 5 July 2017, in final form 2 April 2018)

\begin{abstract}
Surface flux perturbations (heat, freshwater, and wind) due to an increase of atmospheric $\mathrm{CO}_{2}$ cause significant intermodel spread in ocean heat uptake; however, the mechanism underlying their impact is not very well understood. Here, we use ocean model experiments to isolate the impact of each perturbation on the ocean heat uptake components, focusing on surface heat flux anomalies caused directly by atmospheric $\mathrm{CO}_{2}$ increase (passive) and indirectly by ocean circulation change (active). Surface heat flux perturbations cause the passive heat uptake, while all the surface flux perturbations influence ocean heat uptake through the active component. While model results have implied that the active component increases ocean heat uptake because of the weakening of the Atlantic meridional overturning circulation (AMOC), we find that it depends more on the shallow circulation change patterns. Surface heat flux perturbation causes most of the AMOC weakening, yet it causes a net global active heat loss ( $12 \%$ of the total uptake), which occurs because the active heat loss in the tropical Pacific through the subtropical cell weakening is greater than the active heat gain in the subpolar Atlantic through AMOC weakening. Freshwater perturbation weakens the AMOC a little more, but increases the subpolar Atlantic heat uptake a great deal through a large weakening of the subpolar gyre, thereby causing a large global active heat gain ( $34 \%$ of the total uptake). Wind perturbation also causes an active heat loss largely through the poleward shift of the Southern Hemisphere subtropical cells.
\end{abstract}

\section{Introduction}

The rate of global warming is determined by the rate at which the ocean takes up surface heat flux anomalies, which in turn is determined by the ocean circulation pattern and magnitude. Atmospheric $\mathrm{CO}_{2}$ increase not only causes surface heat flux anomalies but also surface freshwater and wind changes. Each $\mathrm{CO}_{2-}$ induced surface flux perturbation contributes to a change in the pattern and magnitude of ocean circulation (Mikolajewicz and Voss 2000), and therefore contributes to ocean heat uptake. For example, surface freshwater perturbations are shown to weaken the ocean meridional heat transport, and increase the Atlantic heat content change and sea level rise (Smith et al. 2014; Bouttes et al. 2014; Sévellec and Fedorov 2016; Sévellec et al. 2017). In fact, surface flux perturbations are shown to be a major source of spread among

${ }^{\text {a }}$ Current affiliation: George Mason University, Fairfax, Virginia.

Corresponding author: Oluwayemi A. Garuba, oluwayemi. garuba@pnnl.gov model estimates of ocean heat uptake (Huber and Zanna 2017). To understand the intermodel spread in sea level rise estimates caused by surface flux perturbations, a Flux-Anomaly-Forced Model Intercomparison Project (FAFMIP) was initiated to compare different model responses to similar surface flux perturbations (Gregory et al. 2016). The goal of this study, however, is to understand the processes that determine the rate of ocean heat uptake by isolating and quantifying the role of the individual surface flux perturbations.

One way to analyze the complex ocean heat uptake process is through a decomposition into passive and active components. The passive component is due to the absorption of anomalous surface heat fluxes directly caused by the radiative warming of the atmosphere due to $\mathrm{CO}_{2}$ concentration increase, while the active component is due to the absorption of the anomalous surface heat fluxes indirectly caused by the ocean circulation change response through the redistribution of the reservoir sea surface temperature (SST) gradients. This active component is often associated with the weakening of the Atlantic meridional overturning circulation (AMOC), which is shown to be a robust feature in global warming 
experiments. AMOC weakening significantly increases heat uptake in the North Atlantic by the following process: the weakened AMOC reduces northward heat transport, cooling off the North Atlantic relative to what it would be without the AMOC slowdown, and the resulting lower SST makes the ocean absorb more heat from the atmosphere (Banks and Gregory 2006; Xie and Vallis 2012; Marshall et al. 2015). In idealized Atlantic-only ocean model experiments, Xie and Vallis (2012) show that the redistribution resulting from the AMOC slowdown also increases the penetration speed of temperature anomalies. Garuba and Klinger (2016) introduce a method for isolating and quantifying this active heat uptake component (or redistribution feedback) in an ocean-only global warming experiment designed to weaken the AMOC, and also find that most of the active heat uptake occurs in the North Atlantic.

Here, we isolate the role of each surface flux perturbation (i.e., temperature, salinity, and wind) in the total ocean heat uptake by quantifying their individual contributions to the passive and active heat uptake components in each basin and globally. To do this, we employ the passive and active ocean heat uptake decomposition method introduced in the study of Garuba and Klinger (2016). The global warming experiment of Garuba and Klinger (2016) was designed to weaken the AMOC through buoyancy flux perturbations only (i.e., both heat and freshwater fluxes), which presumably contribute most of the active uptake. Here, we apply this decomposition to a set of sensitivity experiments designed to isolate the impact of each surface flux perturbation on ocean circulation. By isolating the circulation change patterns contributing most to the active heat uptake, we show that the active heat uptake is more sensitive to shallow circulation changes than to the deep AMOC weakening, and the largest contribution to the ocean heat uptake increase occurs in the North Atlantic as a result of the subpolar gyre weakening caused by surface freshwater perturbation.

\section{Experimental design}

\section{a. Model and data}

The response of a global-domain ocean model to surface flux perturbations is examined using the Parallel Ocean Program, version 2.0 (POP2.0; Smith and Gent 2002). The ocean model uses approximately $1^{\circ}$ horizontal resolution and a tilted pole grid. Eddies are represented by the Gent-McWilliams parameterization (Gent et al. 1995), with a diffusion coefficient of $1.25 \times 10^{3} \mathrm{~m}^{2} \mathrm{~s}^{-1}$ both for the bolus and Redi parts. Vertical turbulent mixing is represented with the K-profile parameterization (Large et al. 1994), with a background diffusivity of $1 \times 10^{-5} \mathrm{~m}^{2} \mathrm{~s}^{-1}$, and convection is represented by strong vertical diffusion. The same model parameters are used for control and perturbation experiments.

The surface forcings are derived from the fully coupled preindustrial control (piControl) and abrupt $\mathrm{CO}_{2-}$ quadrupling $\left(4 \times \mathrm{CO}_{2}\right)$ experiments from phase 5 of the Coupled Model Intercomparison Project (CMIP5; Taylor et al. 2012), using the Community Climate System Model, version 4 (CCSM4; Gent et al. 2011). The CCSM4 piControl run has nonevolving preindustrial $\mathrm{CO}_{2}$ and atmospheric conditions imposed, while the CCSM4 $4 \times \mathrm{CO}_{2}$ experiment is initialized from piControl run at year 1850 , but with atmospheric $\mathrm{CO}_{2}$ instantaneously quadrupled.

As in Xie and Vallis (2012), the surface heat flux and freshwater fluxes for our POP experiments are derived using restoring boundary formulation

$$
\begin{aligned}
Q & =\alpha\left(T_{*}-T_{s}\right) \quad \text { and } \\
Q_{s} & =\alpha\left(S_{*}-S_{s}\right) .
\end{aligned}
$$

Variables $Q$ and $Q_{s}$ are the POP model surface heat and virtual salinity fluxes, respectively; $T_{*}$ and $S_{*}$ are the target surface temperature or salinity fields derived from the fully coupled model, respectively; and $T_{s}$ and $S_{s}$ are the POP model surface temperature and salinity fields, respectively. The target temperature and salinity forcings, $T_{*}$ and $S_{*}$, are derived also using Eqs. (1) and (2), by solving for $T_{*}$ and $S_{*}$ using monthly climatology means of $Q, Q_{s}, S_{s}$, and $T_{s}$ diagnosed from the fully coupled model output. The restoring strength is given by $\alpha=40 \mathrm{~W} \mathrm{~m}^{-2} \mathrm{~K}^{-1}$. Wind stress field from the fully coupled CCSM4 model output is directly applied to the POP model experiments.

\section{b. Experiments}

The POP control is integrated to near-equilibrium using all surface forcings derived from the fully coupled CCSM4 piControl run. Target temperature and salinity fields $\left(T_{*}\right.$ and $S_{*}$ ) are derived from the monthly climatology of SST, sea surface salinity (SSS), and surface heat and freshwater fluxes of the nearly equilibrated last 100 years of the piControl, and initialized from the start of this 100 -yr period. The POP control run is spun up for 500 years using the tracer acceleration method (Bryan 1984), followed by another 500 years with conventional time stepping. Perturbation experiments are 100-yr-long simulations each, initialized from a near-equilibrium period (year 901) of the POP control run. Three perturbation experiments are performed; each is forced with a different combination of surface fluxes derived 
TABLE 1. List of experiments. (piCtrl is piControl experiment, Ctrl is Control, and Abrt is $4 \times \mathrm{CO}_{2}$ abrupt increase experiment.)

\begin{tabular}{lllll}
\hline \hline \multicolumn{1}{c}{ Expt name } & \multicolumn{1}{c}{ Initial } & Wind forcing & Salinity forcing & Temp forcing \\
\hline Control & CCSM4 piCtrl & CCSM4 piCtrl & CCSM4 piCtrl & CCSM4 piCtrl \\
Temp perturbation $\left(\mathrm{T}_{\text {pert }}\right)$ & POP Ctrl & CCSM4 piCtrl & CCSM4 piCtrl & CCSM4 Abrt \\
Temp-salinity perturbation $\left(\mathrm{TS}_{\text {pert }}\right)$ & POP Ctrl & CCSM4 piCtrl & CCSM4 Abrt & CCSM4 Abrt \\
Temp-salinity-wind $\left(\mathrm{TSW}_{\text {pert }}\right)$ & POP Ctrl & CCSM4 Abrt & CCSM4 Abrt & CCSM4 Abrt \\
\hline
\end{tabular}

from both the coupled model piControl and $4 \times \mathrm{CO}_{2}$ experiments (see Table 1). Each perturbation experiment, however, uses the surface target temperature field derived from the fully coupled $4 \times \mathrm{CO}_{2}$ experiment.

In the temperature perturbation experiment $\left(\mathrm{T}_{\text {pert }}\right)$, only the target temperature forcing $T_{*}$ is derived from $4 \times \mathrm{CO}_{2}$; wind forcing and target salinity are derived from the piControl. The temperature-salinity perturbation experiment $\left(\mathrm{TS}_{\text {pert }}\right)$ derives its target values for both temperature and salinity $\left(T_{*}\right.$ and $S_{*}$ ) from $4 \times$ $\mathrm{CO}_{2}$, while the wind forcing is from the piControl. Comparing the $\mathrm{T}_{\text {pert }}$ and $\mathrm{TS}_{\text {pert }}$ experiments isolates the impact of the surface heat and freshwater flux perturbations on the thermohaline circulation and heat uptake. For the temperature-salinity-wind perturbation experiment $\left(\mathrm{TSW}_{\text {pert }}\right), 4 \times \mathrm{CO}_{2}$ supplies all three surface forcings; comparing the $\mathrm{TS}_{\text {pert }}$ and $\mathrm{TSW}_{\text {pert }}$ isolates the impact of wind perturbations on heat uptake. The underlying assumption for this experimental design is that the ocean circulation response is linear; therefore, the total response resulting from all surface flux perturbations can be treated as the sum of changes caused by each surface flux perturbation in isolation. The validity of this assumption is shown in the study of Mikolajewicz and Voss (2000), where they use several partially coupled sensitivity experiments to show that the circulation change in the fully coupled simulation is the sum of the partially coupled experiments with individual surface flux changes prescribed.

Our POP ocean-only experiment is comparable to the fully coupled experiment. The AMOC strength in the POP control is smaller than in the fully coupled piControl; similarly, the AMOC weakens less in $\mathrm{TSW}_{\text {pert }}$ than in $4 \times \mathrm{CO}_{2}$ (Figs. 1a,b and 1c,d). Nevertheless, the ocean heat uptake in $\mathrm{TSW}_{\text {pert }}$ shows similar temperature anomaly distribution, although with not as deep penetration because of its shallower AMOC (Figs. 1e,f). The $4 \times \mathrm{CO}_{2}$ experiment has a net heat content increase of $37.4 \times 10^{23} \mathrm{~J}$, while it is $29.3 \times 10^{23} \mathrm{~J}$ for the $\mathrm{TSW}_{\text {pert }}$ experiment by the end of the 100 th year of the simulation. Note also that our ocean-only model is forced with near equilibrium monthly climatological surface conditions for both the control and perturbation experiments. This removes interannual and higherfrequency atmospheric weather noise associated with the fully coupled model and improves the signal-tonoise ratio, while retaining the annual cycle for both experiments. For the perturbation experiments, surface conditions are instantaneously forced with nearequilibrium conditions from the $4 \times \mathrm{CO}_{2}$ experiment. Therefore, the surface flux evolution in our perturbation experiments is different from the one in the $4 \times \mathrm{CO}_{2}$ experiment, in which surface flux anomalies respond more slowly to instantaneous $\mathrm{CO}_{2}$ quadrupling. Nevertheless, this formulation ensures the ocean approaches a similar equilibrium state as the coupled model but isolates the transient response associated only with the ocean (cf. Figs. 1e and 1f).

\section{c. Passive tracers}

Following the tracer approach in previous studies (Banks and Gregory 2006; Xie and Vallis 2012; Marshall et al. 2015; Garuba and Klinger 2016), we isolate the passive and active (redistributive) temperature anomalies and heat uptake in the three warming experiments. Using overbars to denote values in the control experiment and primes to denote anomalies (the difference between perturbation experiment and the control), the advective-diffusive equation for the temperature anomaly $T^{\prime}$ can be written as follows:

$$
\frac{\partial T^{\prime}}{\partial t}=Q^{\prime}-\nabla \cdot\left(v^{\prime} \bar{T}+v T^{\prime}\right)
$$

where $Q^{\prime}$ is the surface heat flux anomaly and $v$ represents the ocean circulation including all ocean transport processes in a perturbation experiment. We can define the passive temperature anomaly response to a given surface heat flux perturbation $Q_{A}^{\prime}$ as a passive tracer $T_{A}^{\prime}$, which is advected by the same velocity field

$$
\frac{\partial T_{A}^{\prime}}{\partial t}=Q_{A}^{\prime}-\nabla \cdot\left(v T_{A}^{\prime}\right)
$$

where $Q_{A}^{\prime}$ is a surface forcing we will specify shortly. There is no passive tracer in the control run, so $\bar{T}_{A}=0$, and Eq. (4) has no term analogous to $v^{\prime} \bar{T}$ in Eq. (3). The difference between the passive temperature anomaly and the actual temperature anomaly is the redistributive temperature anomaly $T_{R}^{\prime}=T^{\prime}-T_{A}^{\prime}$, which allows the difference between Eqs. (3) and (4) to be written as 
(a) Control MOC (CCSM4)

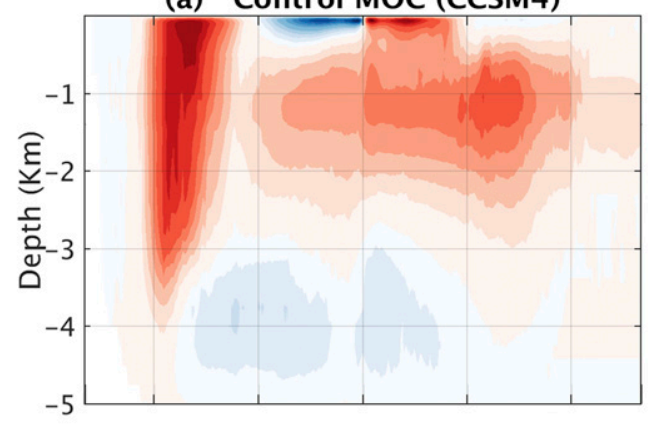

(c) MOC anomaly (CCSM4)

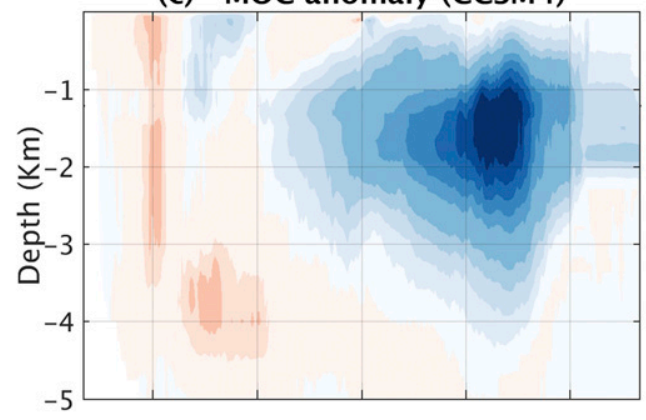

(e) Temperature anomaly (CCSM4)

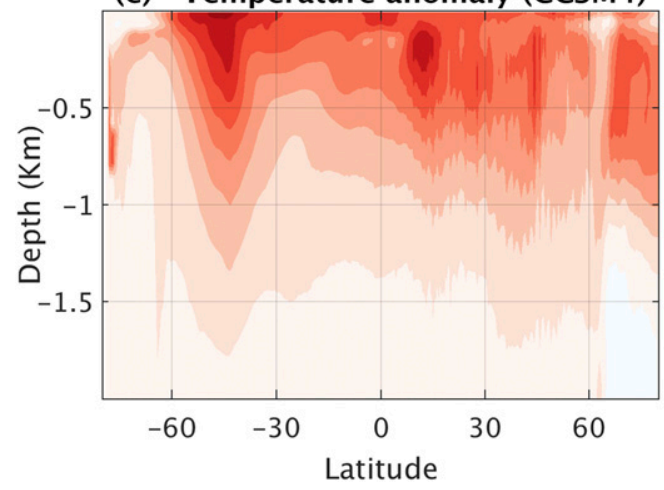

(b) Control MOC (POP)

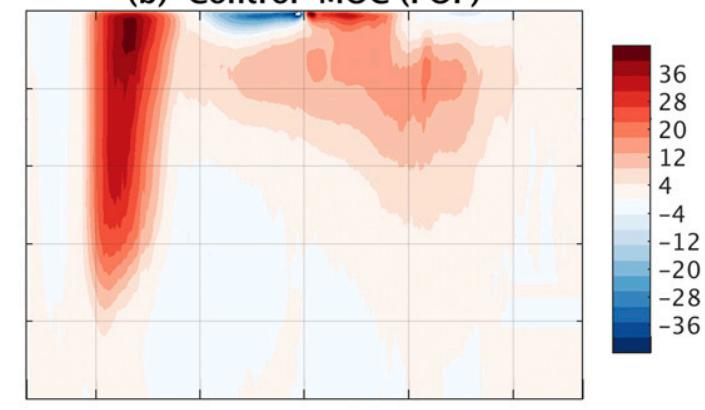

(d) MOC anomaly (POP)

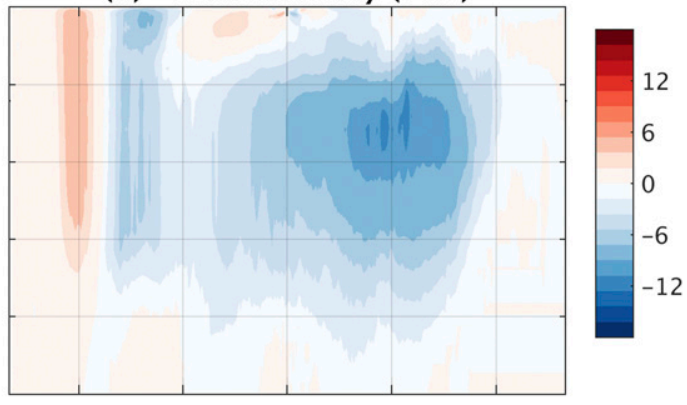

(f) Temperature anomaly (POP)

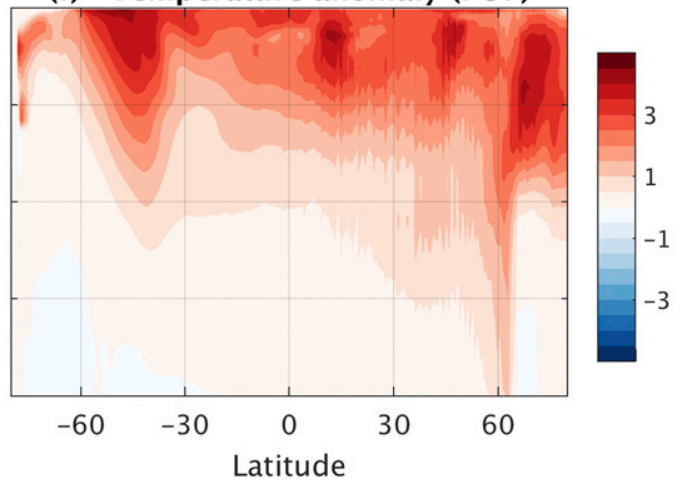

FIG. 1. Meridional overturning streamfunction and its anomaly in (a),(c) the fully coupled CCSM4 from CMIP5 and (b),(d) the POP model $4 \times \mathrm{CO}_{2}$ abrupt increase simulation (Sv). Zonally averaged temperature anomalies in (e) the fully coupled CCSM4 from CMIP5 and (f) the POP model $4 \times \mathrm{CO}_{2}$ abrupt increase simulation $\left({ }^{\circ} \mathrm{C}\right)$.

$$
\frac{\partial T_{R}^{\prime}}{\partial t}=Q^{\prime}-Q_{A}^{\prime}-\nabla \cdot\left(v^{\prime} T+v T_{R}^{\prime}\right)
$$

We call $T_{R}^{\prime}$ the redistributive temperature anomaly because the $v^{\prime} \bar{T}$ term represents the redistribution of the initial temperature field $\bar{T}$ by the changes in circulation. Since $T^{\prime}$ and $T_{A}^{\prime}$ are zero at the beginning of the perturbation run, so is $T_{R}^{\prime}$.

As in Garuba and Klinger (2016), we use two flavors of the variable pair $T_{A}^{\prime}$ and $T_{R}^{\prime}$. For the "total flux" passive tracer $T_{\mathrm{AF}}^{\prime}$, we set $Q_{A}^{\prime}=Q^{\prime}$, and $T_{\mathrm{AF}}^{\prime}$ represents the evolution of $T^{\prime}$ without the redistribution of $\bar{T}$ within the ocean. The corresponding redistribution anomaly
$T_{\mathrm{RF}}^{\prime}=T^{\prime}-T_{\mathrm{AF}}^{\prime}$ has no surface forcing [because in Eq. (5), $\left.Q^{\prime}-Q_{A}^{\prime}=0\right]$, and thus represents only the redistribution of the initial heat content within the ocean and cannot add or remove heat. Consequently $T_{\mathrm{AF}}^{\prime}$ and $T^{\prime}$ have the same volume integral over the entire ocean.

The physical process of rearranging heat within the ocean can change the surface heat flux from the value it would have with a passive temperature anomaly that does not include the redistribution process. For instance, if redistribution cools SST in some region, that region absorbs more heat from the atmosphere than if there were no redistribution. The relationship between surface temperature and heat flux is given by the restoring 
TABLE 2. Variable notation. (T.Anom is temperature anomaly, and redistr. is redistribution.)

\begin{tabular}{|c|c|c|c|c|c|}
\hline Definition & Variable & Flux variable & Time evolution & Global int & tegral \\
\hline Total T.Anom & $T^{\prime}=T-\bar{T}$ & $Q^{\prime}=\alpha\left(T_{*}^{\prime}-T_{s}^{\prime}\right)$ & $\frac{\partial T^{\prime}}{\partial t}=Q^{\prime}-\nabla \cdot\left(\bar{v} T^{\prime}+v^{\prime} T^{\prime}+v^{\prime} \bar{T}\right)$ & $T^{\prime} d v=$ & $Q^{\prime} d a$ \\
\hline Total flux tracer & $T_{\mathrm{AF}}^{\prime}$ & $Q_{A}^{\prime}=Q^{\prime}$ & $\frac{\partial T_{\mathrm{AF}}^{\prime}}{\partial t}=Q^{\prime}-\nabla \cdot\left(\bar{v} T_{\mathrm{AF}}^{\prime}+v^{\prime} T_{\mathrm{AF}}^{\prime}\right)$ & $T_{\mathrm{AF}}^{\prime} d v=$ & $Q^{\prime} d a$ \\
\hline $\begin{array}{l}\text { Total flux } \\
\text { redistr. } \\
\text { T.Anom }\end{array}$ & $T_{\mathrm{RF}}^{\prime}=T^{\prime}-T_{\mathrm{AF}}^{\prime}$ & $Q_{\mathrm{R}}^{\prime}=0$ & $\frac{\partial T_{\mathrm{RF}}^{\prime}}{\partial t}=\nabla \cdot\left(v^{\prime} \bar{T}+\bar{v} T_{\mathrm{RF}}^{\prime}+v^{\prime} T_{\mathrm{RF}}^{\prime}\right)$ & $T_{\mathrm{RF}}^{\prime} d v=0$ & \\
\hline $\begin{array}{l}\text { Same target } \\
\text { tracer }\end{array}$ & $T_{\mathrm{AT}}^{\prime}$ & $Q_{A}^{\prime}=Q_{\mathrm{AT}}^{\prime}=\alpha\left(T_{*}^{\prime}-T_{\mathrm{AT}_{s}}^{\prime}\right)$ & $\frac{\partial T_{\mathrm{AT}}^{\prime}}{\partial t}=Q_{\mathrm{AT}}^{\prime}-\nabla \cdot\left(\bar{v} T_{\mathrm{AT}}^{\prime}+v^{\prime} T_{\mathrm{AT}}^{\prime}\right)$ & $T_{\mathrm{AT}}^{\prime} d v=$ & $Q_{\mathrm{AT}}^{\prime} d a$ \\
\hline Active T. Anom & $T_{\mathrm{RT}}^{\prime}=T^{\prime}-T_{\mathrm{AT}}^{\prime}$ & $Q_{R}^{\prime}=Q_{\mathrm{RT}}^{\prime}=\alpha\left(T_{\mathrm{AT}_{s}}^{\prime}-T_{s}^{\prime}\right)=-\alpha T_{\mathrm{RT}}^{\prime}$ & $\frac{\partial T_{\mathrm{RT}}^{\prime}}{\partial t}=Q_{\mathrm{RT}}^{\prime}+\nabla \cdot\left(v^{\prime} \bar{T}+\bar{v} T_{\mathrm{RT}}^{\prime}+v^{\prime} T_{\mathrm{RT}}^{\prime}\right)$ & $T_{\mathrm{RT}}^{\prime} d v=$ & $Q_{\mathrm{RT}}^{\prime} d a$ \\
\hline
\end{tabular}

condition [Eq. (1)], which for the temperature anomaly is

$$
Q^{\prime}=\alpha\left(T_{*}^{\prime}-T_{s}^{\prime}\right)
$$

By setting $Q_{A}^{\prime}=Q^{\prime}$, we are forcing the tracer $T_{\mathrm{AF}}^{\prime}$ with the surface heat flux based on the temperature anomaly $T^{\prime}$, which includes the redistribution effect. To eliminate the redistribution's influence on surface heat flux, we restore the passive temperature anomaly, instead of the total temperature anomaly, to the target temperature anomaly, that is, "same target" tracer $T_{\mathrm{AT}}^{\prime}$ :

$$
Q_{A}^{\prime}=Q_{A T}^{\prime}=\alpha\left(T_{*}^{\prime}-T_{\mathrm{AT}_{s}}^{\prime}\right)
$$

Such restoring keeps $T_{\mathrm{AT}_{\mathrm{s}}}^{\prime}$ relatively close to $T^{\prime}$, but allows for a different surface heat flux that only depends on the passive temperature response. ${ }^{1}$ The active (or redistribution feedback) surface heat flux is the difference between the total and passive surface heat fluxes, given by $Q_{\mathrm{RT}}^{\prime}=Q^{\prime}-Q_{\mathrm{AT}}^{\prime}$, which from Eqs. (6) and (7) can be written as

$$
Q_{R}^{\prime}=Q_{\mathrm{RT}}^{\prime}=-\alpha\left(T_{\mathrm{RT}_{s}}^{\prime}\right)
$$

Equation (8) clearly shows that redistributive temperature anomalies drive a compensating heat flux, for instance cold $T_{\mathrm{RT}_{s}}^{\prime}$ generating surface warming. As is generally the case with restoring heat flux laws, and as shown in Garuba and Klinger (2016), a relatively small temperature anomaly can lead to a significant surface heat flux change. To summarize, both versions of $T_{\mathrm{R}}^{\prime}$ represent effects associated with circulation changes, but $T_{\mathrm{RF}}^{\prime}$ represents only effects of the temperature redistribution within the ocean, and $T_{\mathrm{RT}}^{\prime}$ also includes the

\footnotetext{
${ }^{1}$ Except for $v^{\prime}$, which is based on the evolution of $T^{\prime}$ and hence is somewhat influenced by redistribution.
}

active uptake, $Q_{\mathrm{RT}}^{\prime}$, which is the feedback between redistributive temperature and surface heat flux (see Table 2 for a summary of notations).

\section{Heat uptake variation among the experiments}

This section compares the passive and active (redistribution feedback) components of heat uptake among the three experiments. Heat here refers to $c_{p} \rho \theta$ (where $\theta$ is any of the tracers, and $c_{p} \approx 4000 \mathrm{~J} \mathrm{~kg}^{-1} \mathrm{~K}^{-1}$ and $\rho \approx 1000 \mathrm{~kg} \mathrm{~m}^{-3}$ are specific heat and density, respectively). "Heat input" into an ocean basin is the integral over-the-top surface of the heat flux $Q^{\prime}$, and "heat uptake" is the change in heat content of a given volume $\left(\int T^{\prime} d v\right)$. We calculate the heat input and uptake for the total perturbation $\left(\int Q^{\prime} d a\right.$ and $\int T^{\prime} d v$, respectively; Table 3), passive component $\left(\int Q_{\mathrm{AT}}^{\prime} d a\right.$ and $\int T_{\mathrm{AT}}^{\prime} d v$, respectively; Table 3$)$, and active component $\left(\int Q_{\mathrm{RT}}^{\prime} d a\right.$ and $\int T_{\mathrm{RT}}^{\prime} d v$, respectively; Table 3). The variable $T_{\mathrm{AF}}^{\prime}$ and its derived redistribution component $T_{\mathrm{RF}}^{\prime}$ will be used to understand the underlying redistributive temperature anomalies creating active heat input distribution.

\section{a. Net global heat uptake}

The three perturbation experiments have very different global heat input or uptake (Fig. 2a, dark gray bars), even though they are forced by the same target surface temperature anomaly $T_{*}^{\prime}$. The global heat input anomaly of the $\mathrm{T}_{\text {pert }}$ experiment is $21.8 \times 10^{23} \mathrm{~J}$, which is equivalent to a temperature change of $\Delta T=\int Q^{\prime} d a /\left(A H c_{p} \rho\right)=$ $1.5 \mathrm{~K}$ for a layer of thickness $H=1000 \mathrm{~m}$ and the ocean surface area $A=3.6 \times 10^{14} \mathrm{~m}^{2}$. Taking total heat input anomaly in $\mathrm{T}_{\text {pert }}$ as the baseline, the $\mathrm{TS}_{\text {pert }}$ experiment has about a $50 \%$ increase $\left(32.5 \times 10^{23} \mathrm{~J}\right)$, while the $\mathrm{TSW}_{\text {pert }}$ experiment has about a $35 \%$ increase $\left(29.4 \times 10^{23} \mathrm{~J}\right)$ in the total heat input of the $\mathrm{T}_{\text {pert }}$ experiment. The passive components of these different global heat inputs, however, does not vary much, and is roughly $25 \times 10^{23} \mathrm{~J}$ in the three experiments (Fig. 2a, light gray bars). The active heat input 
TABLE 3. Time-integrated total, passive, and redistributive surface heat flux $Q^{\prime}, Q_{\mathrm{AT}}^{\prime}$, and $Q_{\mathrm{RT}}^{\prime}$ and temperature anomalies $T^{\prime}, T_{\mathrm{AT}}^{\prime}$, and $T_{\mathrm{RT}}^{\prime}\left(10^{23} \mathrm{~J}\right)$ in the $\mathrm{T}_{\text {pert }}, \mathrm{TS}_{\text {pert }}$, and $\mathrm{TSW}_{\text {pert }}$ experiments, integrated over the 100 -yr run for each ocean.

\begin{tabular}{|c|c|c|c|c|c|c|c|c|c|c|c|c|}
\hline & \multicolumn{4}{|c|}{$\mathrm{T}_{\text {pert }}$} & \multicolumn{4}{|c|}{$\mathrm{TS}_{\text {pert }}$} & \multicolumn{4}{|c|}{$\mathrm{TSW}_{\text {pert }}$} \\
\hline & Global & Indian & Pacific & Atlantic & Global & Indian & Pacific & Atlantic & Global & Indian & Pacific & Atlantic \\
\hline$Q^{\prime} d a$ & 21.8 & 9.6 & 4.9 & 7.3 & 32.5 & 9.0 & 7.8 & 15.7 & 29.4 & 10.0 & 8.2 & 11.2 \\
\hline$Q_{\mathrm{AT}}^{\prime} d a$ & 25.4 & 8.5 & 7.6 & 9.3 & 25.9 & 8.3 & 7.5 & 10.1 & 26.1 & 8.8 & 7.5 & 9.8 \\
\hline$Q_{\mathrm{RT}}^{\prime} d a$ & -3.6 & 1.1 & -2.7 & -2.0 & 6.6 & 0.7 & 0.3 & 5.6 & 3.3 & 1.2 & 0.7 & 1.4 \\
\hline$T^{\prime} d v$ & 21.8 & 4.6 & 11.6 & 5.6 & 32.5 & 6.2 & 13.3 & 13 & 29.4 & 5.5 & 11.2 & 12.7 \\
\hline$T_{\mathrm{AT}}^{\prime} d v$ & 25.4 & 5.4 & 11.7 & 8.3 & 25.9 & 5.6 & 11.6 & 8.7 & 26.1 & 5.6 & 11.6 & 8.7 \\
\hline$T_{\mathrm{RT}}^{\prime} d v$ & -3.6 & -0.8 & -0.1 & -2.7 & 6.6 & 0.6 & 1.7 & 4.3 & 3.3 & -0.1 & -0.4 & 4.0 \\
\hline
\end{tabular}

accounts for the variation of the global heat input in the experiments (Fig. 2a, difference between light and dark gray bars).

The active heat input due to the surface temperature perturbation alone in the $T_{\text {pert }}$ experiment is negative, indicating an active heat loss. The active heat loss in this experiment makes its passive input greater than its total heat input by $3.6 \times 10^{23} \mathrm{~J}$ (Table 1 ; compare also the difference between total and passive heat inputs in Fig. 2a). The active heat input caused by salinity perturbation is the difference between the active heat input from the $\mathrm{TS}_{\text {pert }}$ and $\mathrm{T}_{\text {pert }}$ experiments. Salinity perturbations cause the only positive (and largest magnitude) active heat input $\left(10.2 \times 10^{23} \mathrm{~J}\right.$; Table 3$)$. The active heat input due to the wind perturbation is the difference between the active heat input from the $\mathrm{TSW}_{\text {pert }}$ and $\mathrm{TS}_{\text {pert }}$ experiments. Like temperature perturbation, wind perturbation causes a net global active heat loss of $-3.3 \times 10^{23} \mathrm{~J}$. The total active heat input resulting from all three surface flux perturbations in the $\mathrm{TSW}_{\text {pert }}$ experiment $\left(3.3 \times 10^{23} \mathrm{~J}\right)$ is reduced to approximately $13 \%$ of the passive input because of the active heat loss from surface temperature and wind perturbations. This variation of the global heat input among the experiments through the active component highlights how easily variations in the simulated surface flux response can cause a spread in the simulated ocean heat uptake, even with similar radiative forcing. The active heat losses caused by surface wind and temperature perturbation also show that redistribution may not always increase ocean heat uptake as often assumed.

The similarity in the passive input among the experiments can be explained by the design of the surface forcing in Eq. (7). All three experiments are forced with the same target temperature anomaly $T_{*}^{\prime}$ and restoration time scale $\alpha$. Therefore, differences in the passive heat input $Q_{\mathrm{AT}}^{\prime}$ among the experiments occur only as a result of differences in the ocean passive surface response $T_{\mathrm{AT}}^{\prime}$ among the experiments. We use $\delta$ to refer to differences between any two perturbation experiments. The term $\delta T_{\mathrm{AT}_{s}}^{\prime}$ depends on the difference in transport of passive tracer by the total velocity field, that is, $v T_{\mathrm{AT}_{s}}^{\prime}$ :

$$
\delta\left(v T_{\mathrm{AT}_{s}}^{\prime}\right)=\delta v T_{\mathrm{AT}_{s}}^{\prime}+v \delta T_{\mathrm{AT}_{s}}^{\prime} .
$$

The term $\delta v T_{\mathrm{AT}_{s}}^{\prime}$ is equivalent to $\delta v^{\prime} T_{\mathrm{AT}_{s}}^{\prime}$, which is a higher-order term and expected to be small. The difference in the transport between the experiments will therefore depend only on $v \delta T_{\mathrm{AT}_{s}}^{\prime}$, and will be small as long as $\delta T_{\mathrm{AT}_{s}}^{\prime}$ remains small. By design, $T_{\mathrm{AT}_{s}}^{\prime}$ in all the experiments is restored to the same target value; therefore, $\delta T_{\mathrm{AT}_{s}}^{\prime}$ is small.

On the other hand, the active heat input in Eq. (8) depends on the surface redistributive temperature $T_{\mathrm{RT}_{s}}^{\prime}$. Unlike the $\delta T_{\mathrm{AT}_{s}}^{\prime}$, which is constrained to be small by restoration to the same value, $\delta T_{\mathrm{RT}_{s}}^{\prime}$ is not small. According to Eq. (5), $T_{\mathrm{RT}}^{\prime}$ is caused by $v^{\prime} T$, and because $\bar{T}$ is both large and constant for all the experiments, and $\delta v^{\prime}$ also varies both in magnitude and pattern among the experiments, $\delta v^{\prime} \bar{T}$ is not small; therefore, $T_{\mathrm{RT}_{s}}^{\prime}$ and $Q_{\mathrm{RT}}^{\prime}$ have significant variations among the experiments.

\section{b. Heat uptake distribution among basins}

Here, we define basins to include their sectors of the Southern Ocean, with boundaries there set at longitudes $22^{\circ} \mathrm{E}, 134^{\circ} \mathrm{E}$, and $70^{\circ} \mathrm{W}$. The passive heat input into each basin, like the global passive heat input, are similar for all three experiments (Fig. 2b, light gray bars). The passive heat input is greatest for the Atlantic, where it is about $9.7 \times 10^{23} \mathrm{~J}$ (average among the experiments), slightly less for the Indian Ocean $\left(8.7 \times 10^{23} \mathrm{~J}\right)$, and least for the Pacific, with about $7.5 \times 10^{23} \mathrm{~J}$. The passive heat 
(a) global heat input, T, TS, TSW

(b) basin heat input, T, TS, TSW
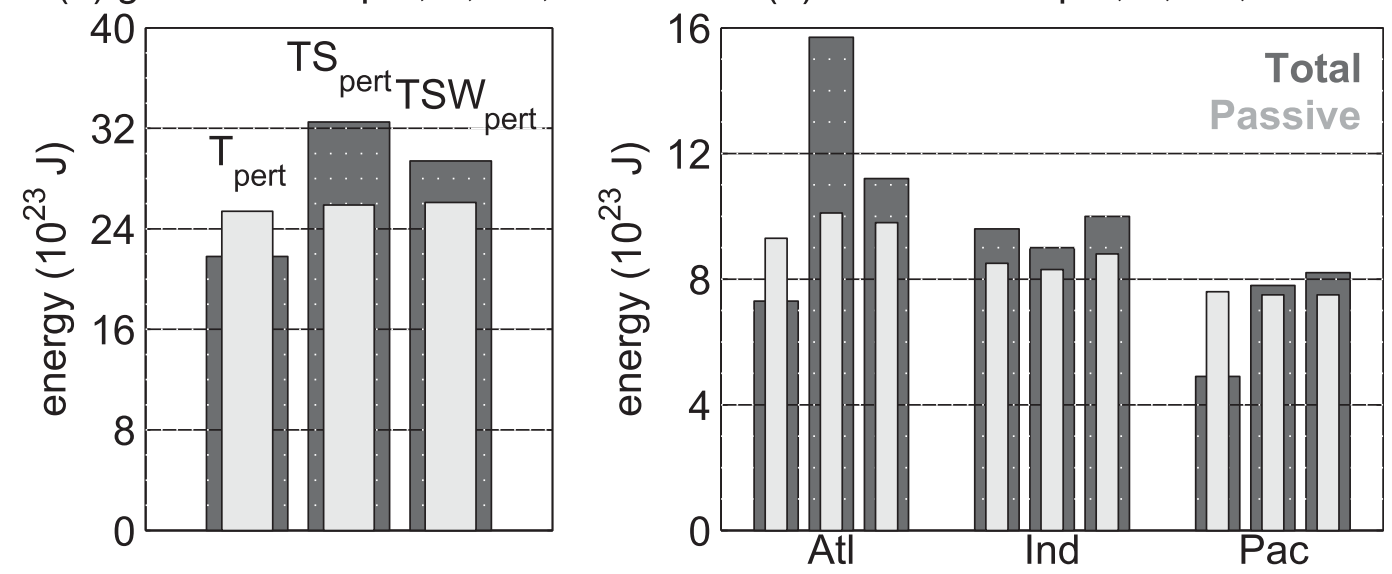

(c) basin heat uptake, T, TS, TSW

FIG. 2. Thermal energy absorbed during the three perturbation experiments for (a) global heat input $\int Q^{\prime} d a$, (b) input in individual basins, and (c) uptake $\int T^{\prime} d v$ in individual basins. Dark and light gray bars represent the total and passive component, respectively; active heat input contribution is given by difference between total and passive. Each group of three bars represents (from left to right) $\mathrm{T}_{\text {pert }}$, $\mathrm{TS}_{\text {pert }}$, and $\mathrm{TSW}_{\text {pert }}$ experiments.

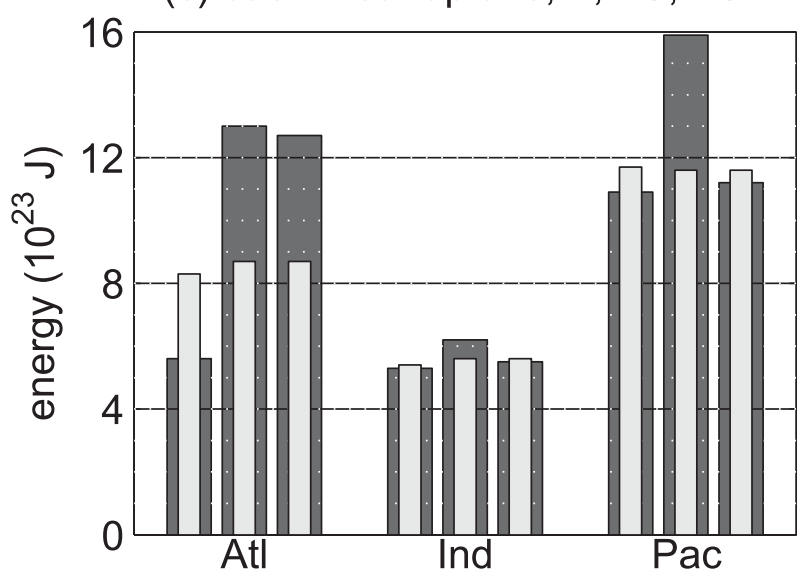

uptake, however, is different, with the largest of $11.6 \times$ $10^{23} \mathrm{~J}$ in the Pacific, $8.5 \times 10^{23} \mathrm{~J}$ in the Atlantic, and the least of $5.5 \times 10^{23} \mathrm{~J}$ in the Indian Ocean (Fig. 2c, dark gray bars). The difference between each basin passive heat input and uptake is explained by interbasin heat transport. As indicated by the similar basin passive heat input and uptake among the experiments, this interbasin passive heat exchange is also similar among the experiments. The heat exchange among the basins is computed as the net heat transport through their respective Southern Ocean boundaries and the Indonesian Throughflow (THF) (the heat transport into the Arctic from the Pacific and Atlantic is relatively small). The Pacific imports some passive heat content from the Atlantic and a greater amount from the Indian Ocean. This large heat export from the Indian Ocean explains its relatively large passive heat input per unit area $(1.18 \times$ $\left.10^{10} \mathrm{~J} \mathrm{~m}^{-2}\right)$ compared to that of the Pacific $(0.42 \times$ $10^{10} \mathrm{~J} \mathrm{~m}^{-2}$ ), despite its weaker gyre circulation. Garuba and Klinger (2016) have an in-depth discussion of the heat exchange among the basins, as well.
Unlike the passive heat input, the active heat input in each basin varies greatly among the experiments (Fig. 2b, difference between bars for passive and total input). We examine the regional distribution of the basin active heat input by partitioning the domain into northern, tropical, and southern zones separated at latitudes $\pm 30^{\circ}$ and the Southern Ocean longitude boundaries mentioned in the preceding paragraph (Fig. 3). In the $\mathrm{T}_{\text {pert }}$ experiment, the negative global active heat input comes from the southern and tropical Atlantic, and tropical Pacific. Although the northern Atlantic active heat input is positive, it is cancelled by a greater active heat output from the southern Atlantic and smaller output in the tropical Atlantic. The tropical Pacific has the largest active heat loss contribution, and expels more heat than the northern Atlantic gains; northern and southern Pacific contributions are smaller and cancel each other.

This large active heat loss in the tropical Pacific is caused by the El Niño-like redistributive surface warming (Fig. 4a). This redistributive warming pattern is a robust response of the tropical Pacific to global 

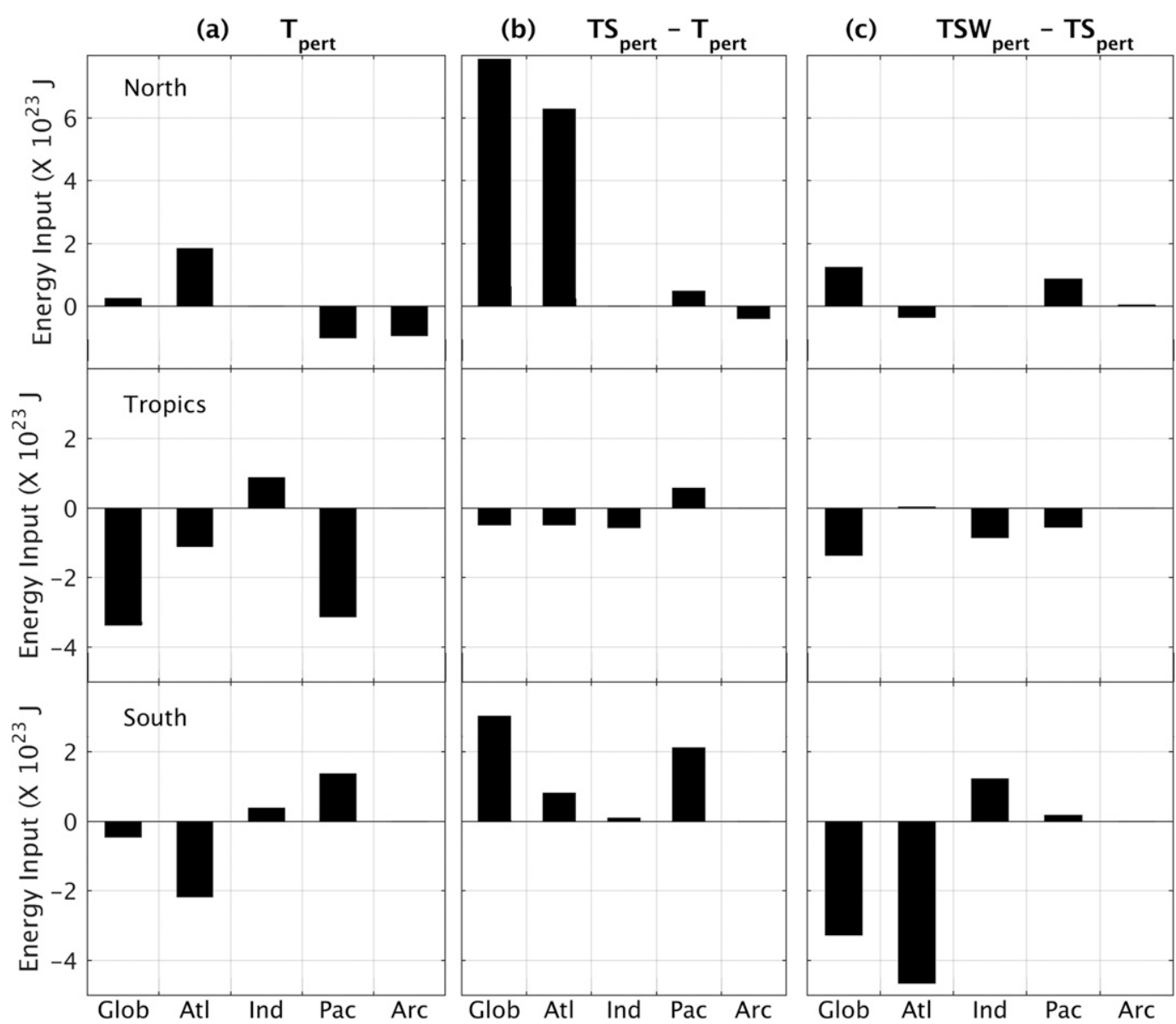

FIG. 3. Active heat input $\int Q_{\mathrm{RT}}^{\prime} d a$ resulting from (a) temperature $\left(\mathrm{T}_{\text {pert }}\right)$, (b) salinity $\left(\mathrm{TS}_{\text {pert }}-\mathrm{T}_{\text {pert }}\right)$, and (c) wind $\left(\mathrm{TSW}_{\text {pert }}-\mathrm{TS}_{\text {pert }}\right)$ perturbations. The active heat input is integrated over the 100 -yr run over the surface of each ocean basin and globally, (top)-(bottom) in the northern $\left(90^{\circ}-30^{\circ} \mathrm{N}\right)$, tropical $\left(30^{\circ} \mathrm{S}-30^{\circ} \mathrm{N}\right)$, and southern $\left(30^{\circ}-90^{\circ} \mathrm{S}\right)$ latitudes.

warming as a result of weakening of the Pacific subtropical cells (Andrews et al. 2015; Luo et al. 2015, 2017). The weakening of the subtropical cell strength is often associated with surface wind; however, the weakening here is not wind driven, because wind is not changed in this experiment. It is also unlikely that the temperature perturbation-induced subtropical cell weakening is caused by wind-induced patterns in the target temperature anomaly distribution. The ocean-only tracer experiments of Luo et al. (2017) with uniform surface warming restoration show that subtropical cell weakening can indeed occur even under uniform surface temperature perturbation. The relatively weak northern Atlantic active heat gain occurs in the subpolar region, and is also caused by the robust redistributive surface cooling of the subpolar Atlantic, which is often associated with the AMOC weakening in it (Fig. 4a).

The large global active heat input caused by salinity perturbation is dominated by active input in the northern
Atlantic; the southern Pacific also gains significant but weaker active heat input (Fig. 3b). This large North Atlantic active heat gain is due to the greater redistributive cooling in the subpolar Atlantic caused by salinity perturbation (Fig. 4b). Subpolar Atlantic cooling is a robust feature in global warming simulations and historical records, and it is often attributed to AMOC weakening (Banks and Gregory 2006; Xie and Vallis 2012; Marshall et al. 2015). Here, however, the salinity-induced North Atlantic active heat gain is more than 3 times the temperature-induced one, although salinity perturbations cause much less AMOC weakening than temperature perturbation, as we will discuss in the next section. This result suggests that subpolar Atlantic cooling may not be fully attributable to the AMOC weakening, a fact that has also been noted in historical warming trends (Drijfhout et al. 2012). This greater impact of salinity perturbation on subpolar Atlantic cooling is also implied in the study of Sévellec and Fedorov (2016), where they show that 
(a) $T_{\text {pert }}$
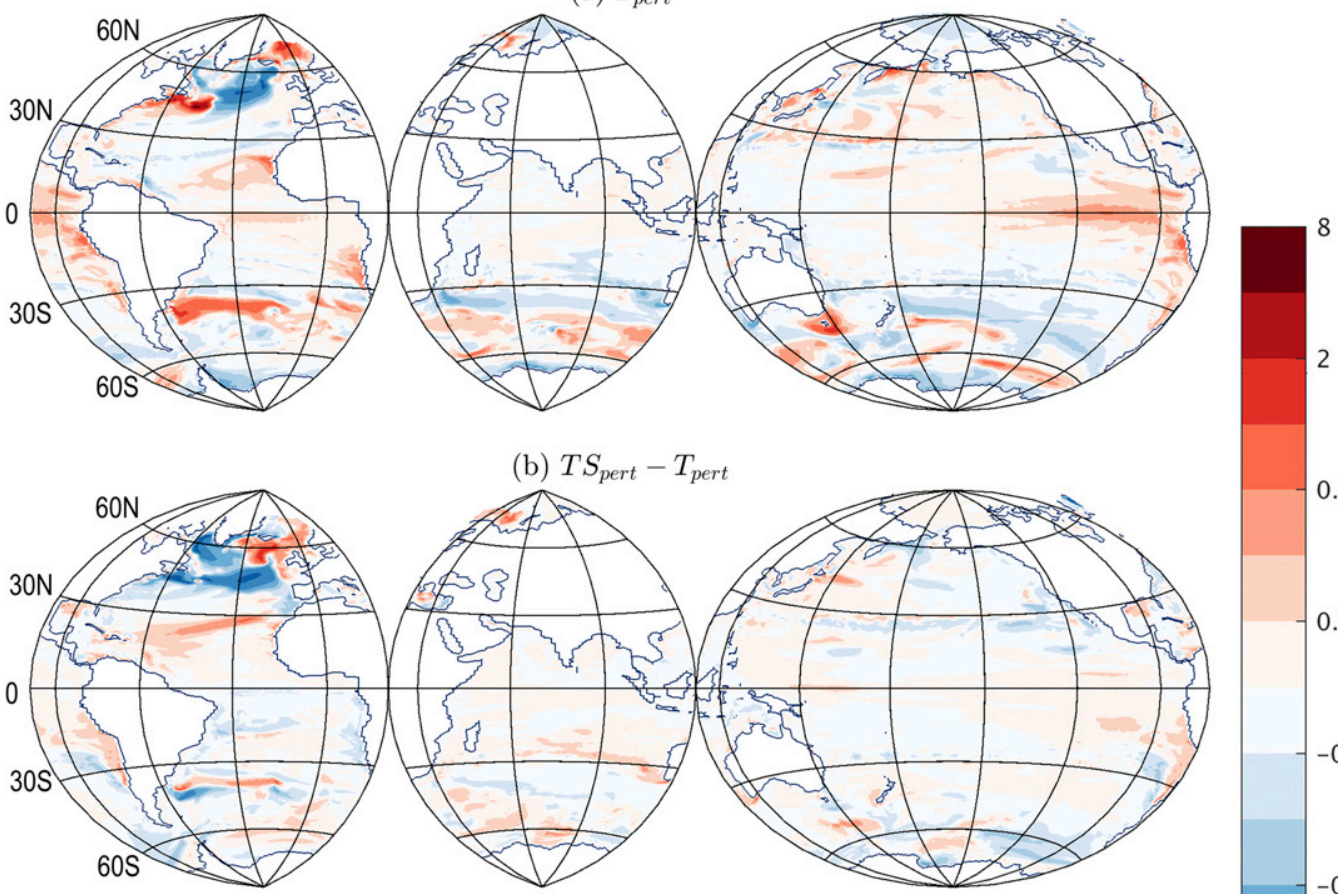

(c) $T S W_{\text {pert }}-T S_{\text {pert }}$

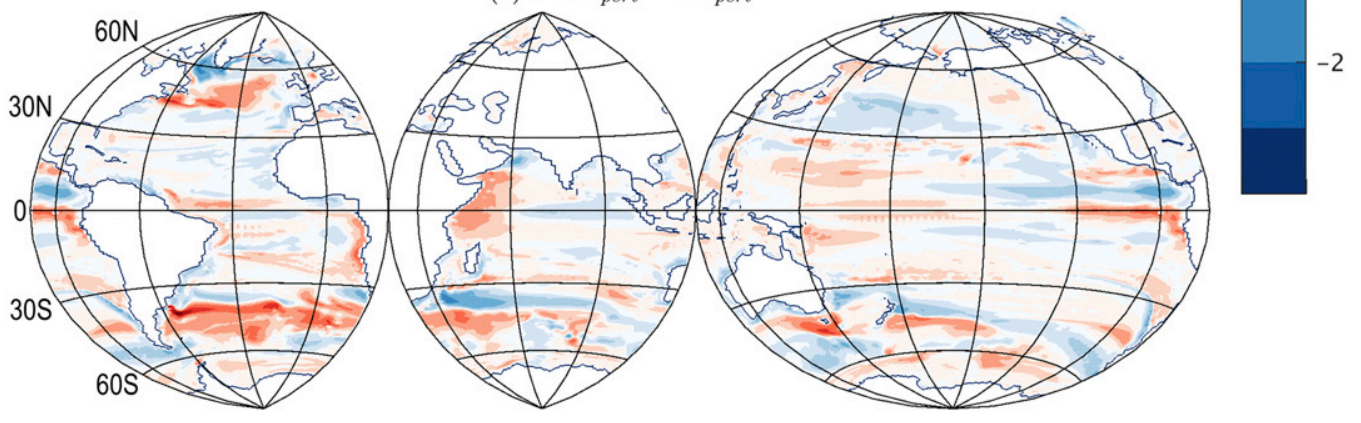

FIG. 4. Surface distribution of the 100-yr-averaged active temperature anomaly $T_{\mathrm{RT}}^{\prime}\left({ }^{\circ} \mathrm{C}\right)$ due to (a) temperature, (b) salinity, and (c) wind perturbations.

compared to surface heat flux perturbation, freshwater perturbation weakens meridional heat transport more, even though it weakens meridional volume transport less, within the first 100 years.

The global active heat loss resulting from the wind perturbation occurs largely in the South Atlantic, with much weaker active heat loss in the tropical Pacific and Indian Oceans (Fig. 3c). Wind perturbation removes about $75 \%$ as much active heat from the South Atlantic as salinity perturbation added in the North Atlantic. The windinduced South Atlantic active heat loss is due to Southern Ocean redistributive warming around $45^{\circ} \mathrm{S}$ (Fig. 4c). This Southern Ocean redistributive warming is also a robust feature of global warming simulations and in observations, which have been attributed to the intensification and poleward shift of western boundary currents around these latitudes (Mikolajewicz and Voss 2000; Yang et al. 2016). It is noteworthy that the tropical Pacific active heat loss resulting from the surface temperature perturbation is much larger than the one caused by wind changes, which is assumed to control the strength of subtropical cells, as we will discuss in section $4 \mathrm{~b}$.

\section{Circulation and redistributive anomaly patterns \\ a. Response to thermohaline forcing}

Temperature and salinity forcing perturbation in the $\mathrm{T}_{\text {pert }}$ and $\mathrm{TS}_{\text {pert }}$ experiments both weaken the thermohaline circulation, yet they cause global active heat input 

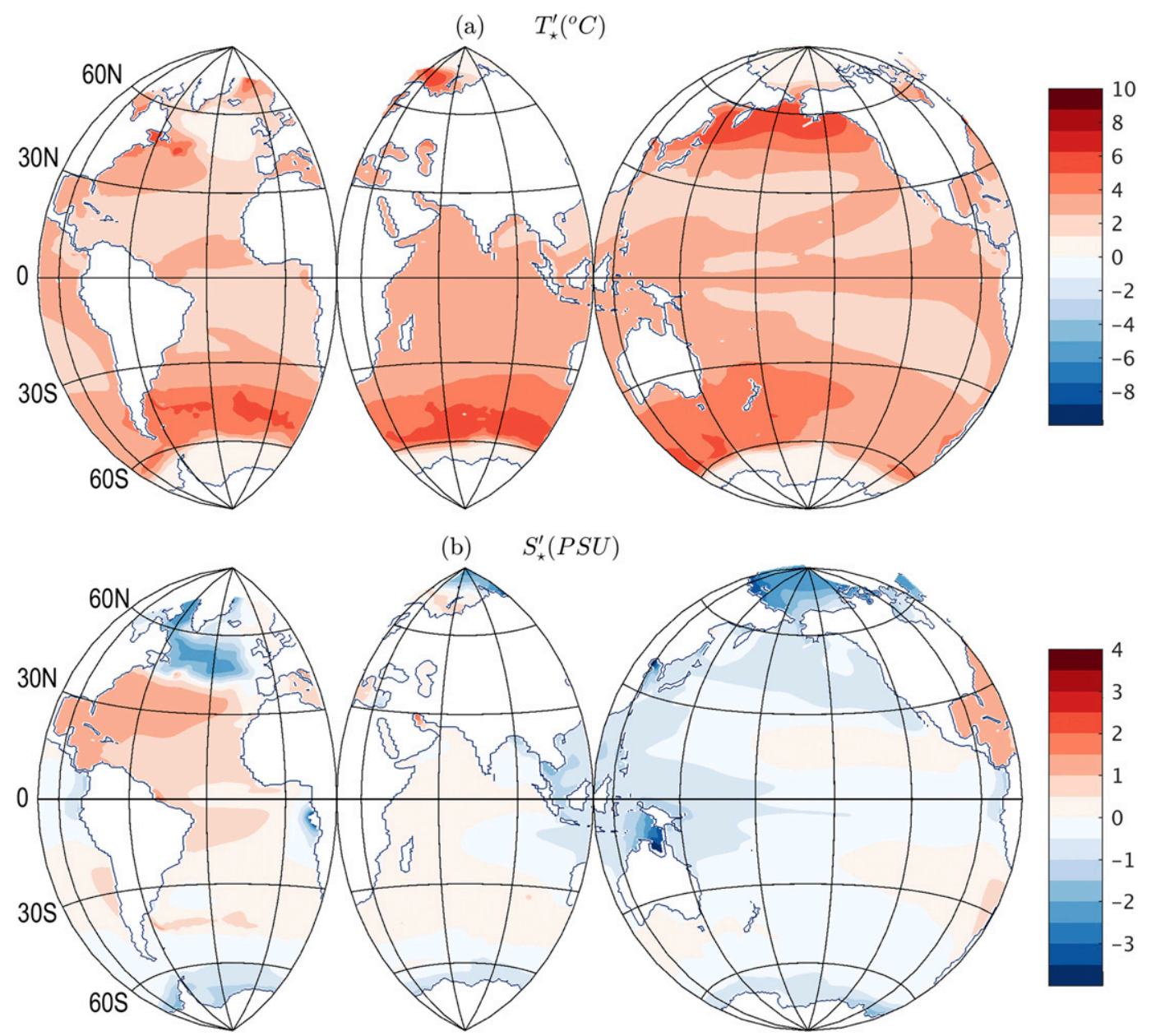

FIG. 5. (a) Surface target temperature $T_{*}^{\prime}$ and (b) salinity $S_{*}^{\prime}$ anomalies used for restoring surface temperature and salinity in the $\mathrm{T}_{\text {pert }}$ and $\mathrm{TS}_{\text {pert }}$ experiments.

with large magnitude difference and opposite signs, mainly because they each cause very different magnitudes of active heat input in the North Atlantic (see section 3a). We consider the circulation change and reservoir redistributive $\left(T_{\mathrm{RF}}^{\prime}\right)$ pattern in the $\mathrm{T}_{\text {pert }}$ and $\mathrm{TS}_{\text {pert }}$ experiments causing this difference in the active heat input in the two experiments. The forcing patterns of target surface temperature anomaly $T_{*}$ and salinity anomaly $S_{*}$ project differently into the AMOC deepwater formation region (Figs. 5a,b). Surface warming is weakest in the subpolar North Atlantic, although there is substantial warming in the Labrador Sea and near Iceland. In contrast, the salinity forcing perturbation has the strongest freshening in the subpolar North Atlantic and Arctic regions.

Temperature perturbation and salinity cause different magnitudes of AMOC weakening, although both perturbations cause similar spatial patterns of AMOC weakening in the deep ocean (cf. Figs. 6a and 6b). Surface warming weakens the AMOC in $\mathrm{T}_{\text {pert }}$ by $6 \mathrm{~Sv}(1 \mathrm{~Sv} \equiv$ $\left.10^{6} \mathrm{~m}^{3} \mathrm{~s}^{-1}\right)$, and the additional salinity perturbation in the $\mathrm{TS}_{\text {pert }}$ weakens it further by $3 \mathrm{~Sv}$. This greater impact of surface heat flux perturbation on AMOC weakening compared to surface freshwater perturbation is also a robust feature of global warming climate models (Mikolajewicz and Voss 2000; Gregory et al. 2005; Weaver et al. 2007; Sévellec and Fedorov 2016; Sévellec et al. 2017). However, the global active heat input associated with these magnitudes of AMOC weakening is different from what is often expected from AMOC slowdown. If AMOC weakening alone determined the global active heat input, the $\mathrm{T}_{\text {pert }}$ experiment would have a positive global active heat input, but with slightly smaller magnitude than the one in the $\mathrm{TS}_{\text {pert }}$ experiment.

Despite their similar deep circulation change patterns, the shallow circulation change patterns resulting from the two perturbations are different (cf. Figs. $6 \mathrm{a}$ and $6 \mathrm{~b}$ above dark line). In the top 500-m subpolar region, 


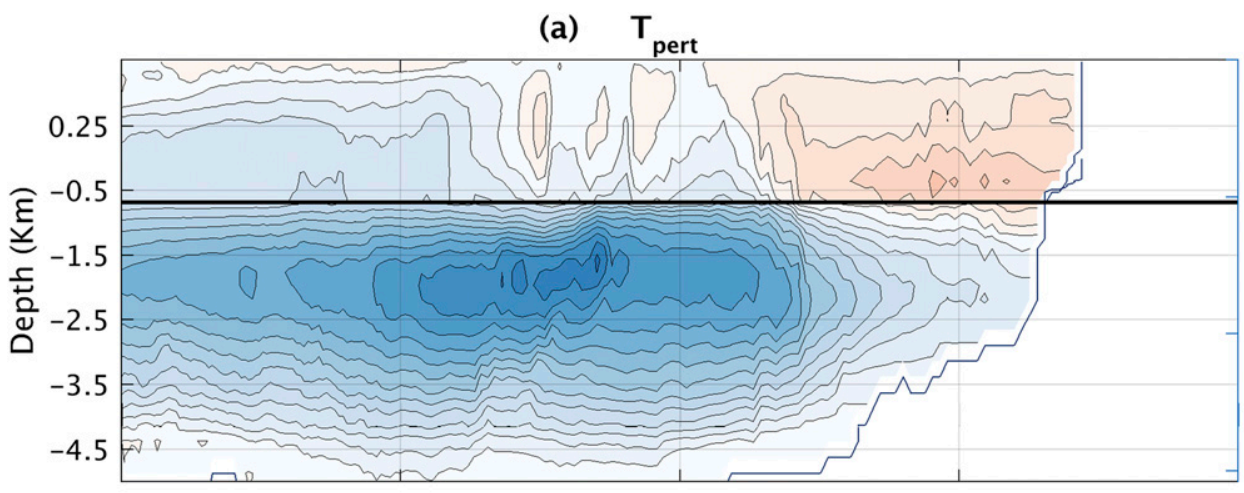

(b) $\mathrm{TS}_{\text {pert }}-\mathrm{T}_{\text {pert }}$

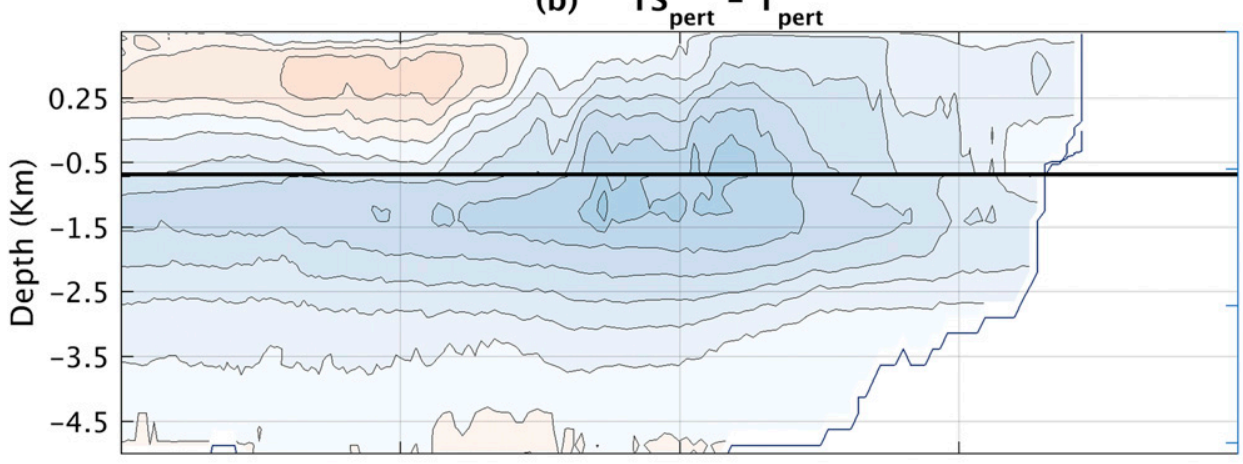

(c) $\mathrm{TS}_{\mathrm{pert}}$

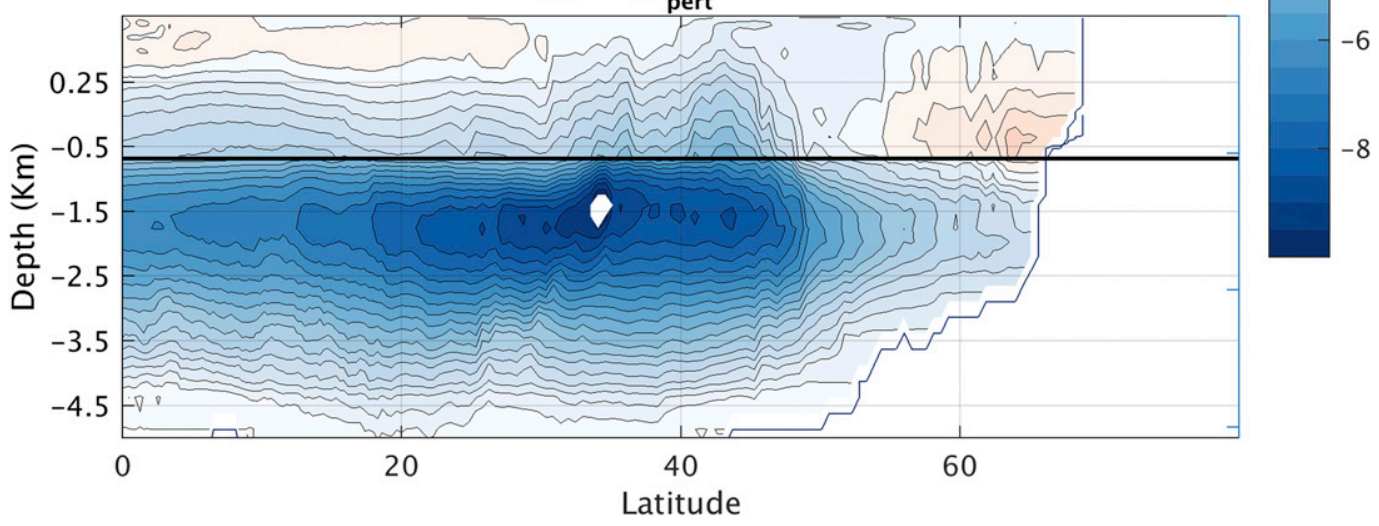

FIG. 6. Atlantic meridional overturning streamfunction anomaly averaged over the 100 -yr simulation in (a) the $\mathrm{T}_{\text {pert }}$ experiment, (b) the difference between the $\mathrm{TS}_{\text {pert }}$ and $\mathrm{T}_{\text {pert }}$ experiments, and (c) the $\mathrm{TS}_{\text {pert }}$ experiment. The black line separates the enlarged top $500 \mathrm{~m}$. (Contour interval is $0.5 \mathrm{~Sv}$.)

north of about $45^{\circ} \mathrm{N}$, the circulation anomalies caused by temperature and salinity perturbations are opposite (cf. Figs. 6a and 6b); $\mathrm{T}_{\text {pert }}$ has a northward-flow anomaly, which strengthens the background northward flow here, but $\mathrm{TS}_{\text {pert }}-\mathrm{T}_{\text {pert }}$ has a southward-flow anomaly, weakening the background flow. Similarly, in the top $500-\mathrm{m}$ tropical region, south of about $35^{\circ} \mathrm{N}$, the circulation anomaly in the $T_{\text {pert }}$ experiment is largely southward, while in $\mathrm{TS}_{\text {pert }}-\mathrm{T}_{\text {pert }}$ it is largely northward. These shallow circulation anomalies in the subpolar
Atlantic explain the differences in the active heat input in the $\mathrm{T}_{\text {pert }}$ and $\mathrm{TS}_{\text {pert }}$ experiments. Because of the closeness to the surface, shallow circulation changes have a greater impact on the active heat input through the surface redistributive temperature anomalies, even though they are much smaller than the deep circulation anomalies.

To see this more clearly, we examine the zonal-average meridional velocity anomalies caused by surface temperature and salinity perturbations (Figs. 7a,b). The 

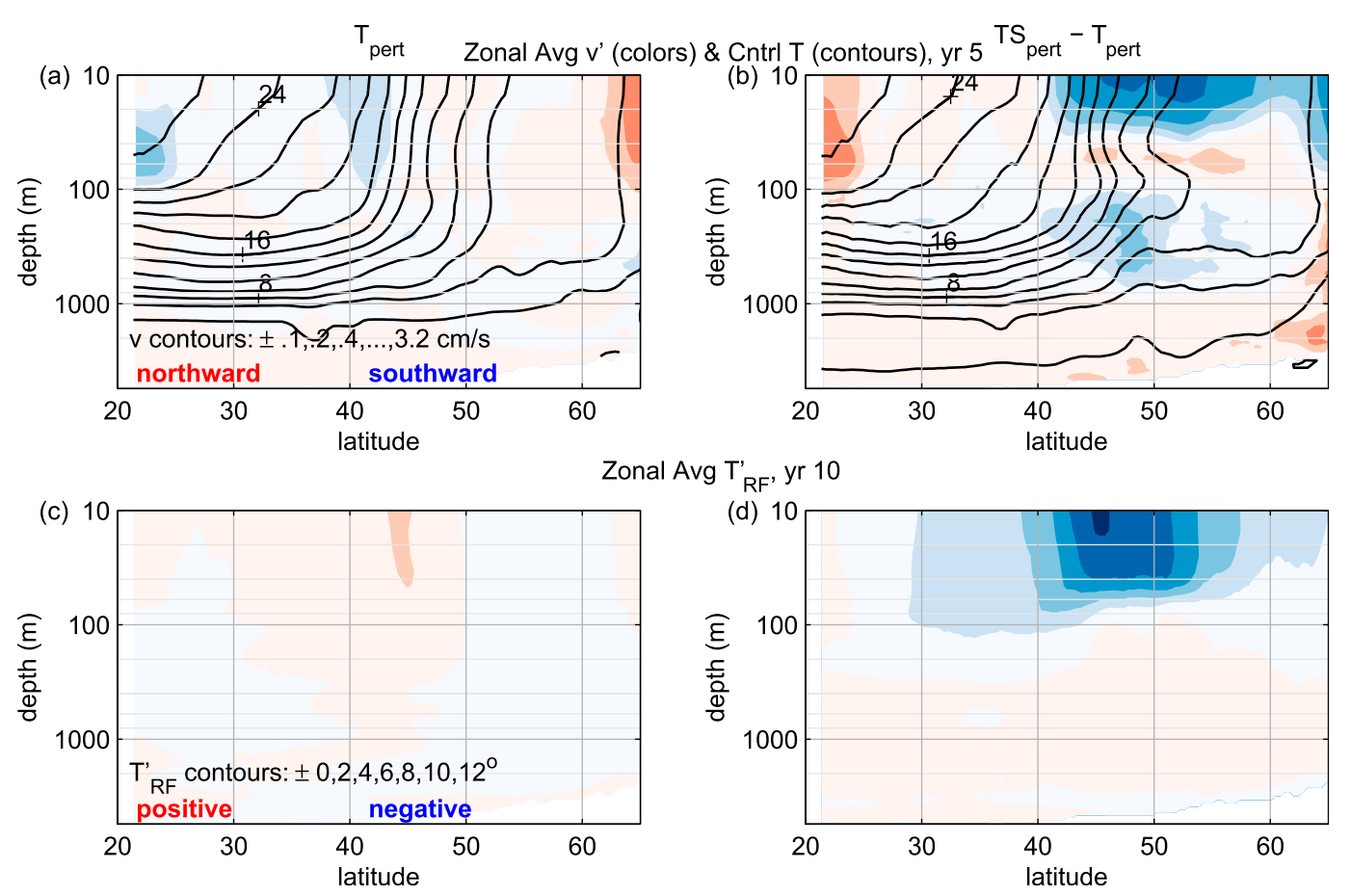

FIG. 7. Zonally averaged meridional velocity [color shading, interval defined in (a)] resulting from (a) temperature $\left(\mathrm{T}_{\text {pert }}\right)$ and (b) salinity $\left(\mathrm{TS}_{\text {pert }}-\mathrm{T}_{\text {pert }}\right)$ perturbations and control temperature (contours; ${ }^{\circ} \mathrm{C}$ ) in the North Atlantic at year 5. North Atlantic redistributive temperature anomalies [ ${ }^{\circ} \mathrm{C}$; color shading, interval defined in (c)] resulting from $(\mathrm{c})$ temperature $\left(\mathrm{T}_{\text {pert }}\right)$ and $(\mathrm{d})$ salinity $\left(\mathrm{TS}_{\text {pert }}-\mathrm{T}_{\text {pert }}\right)$ perturbations at year 10.

$\mathrm{TS}_{\text {pert }}-\mathrm{T}_{\text {pert }}$ flow anomaly is strongly southward in a $50-\mathrm{m}$ thick region near $50^{\circ} \mathrm{N}$, whereas in $\mathrm{T}_{\text {pert }}$, none of the near-surface flow anomaly is that strong. Moreover, strong southward flow near the surface in Fig. $7 \mathrm{~b}$ is in a region of strong meridional gradient in zonal-average temperature in the control run (contours in Figs. 7a,b). Thus the $-v^{\prime} \partial \bar{T} / \partial y$ term in Eq. (5) has a strongly negative value in just the place where $T_{\mathrm{RF}}^{\prime}$ has strong cooling in $\mathrm{TS}_{\text {pert }}$ but not in $\mathrm{T}_{\text {pert }}$ (Figs. $7 \mathrm{c}, \mathrm{d}$ ). The near-surface southward-flow anomaly shown in Fig. 7b starts quickly (year 5 is shown) and persists throughout $\mathrm{TS}_{\text {pert }}$. Similarly, $T_{\mathrm{RF}}^{\prime}$ continues to cool there, although at a decreasing rate as the system evolves toward equilibration.

Furthermore, we compare the volume transport change in the subpolar gyre (SPG) related to the shallow circulation changes, and the AMOC volume transport change related to the deep circulation changes (Figs. 8a,d). The volume transport is estimated using the location of the maximum volume transport at their respective streamfunctions. The subpolar gyre shows a lot more volume transport weakening in the $\mathrm{TS}_{\text {pert }}$ than in the $\mathrm{T}_{\text {pert }}$ experiment, whereas the $T_{\text {pert }}$ show more volume transport weakening in the deep circulation than the $\mathrm{TS}_{\text {pert }}$ (Figs. 8a,b). This difference in volume transport explains the great redistributive heat content loss in the top $500 \mathrm{~m}$ in the $\mathrm{TS}_{\text {pert }}$ compared to the $T_{\text {pert }}$, whereas in the deep ocean the $T_{\text {pert }}$ loses more redistributive heat content than the $\mathrm{TS}_{\text {pert }}$ (Figs. 8c,d). Note that the redistributive heat content anomaly is a measure of the heat transport anomaly caused only by circulation changes, and not that due to the anomalous surface heat fluxes. Therefore, the North Atlantic active heat input in the two experiments is indeed related to the near-surface redistributive heat content changes due to shallow circulation changes, rather than to deep circulation changes.

\section{b. Response to wind forcing}

The active heat loss resulting from the wind perturbation occurs mainly in the Southern Ocean because of the redistributive warming anomaly it causes around $45^{\circ} \mathrm{S}$, extending from the South Atlantic into the Indian Ocean sector (cf. Fig. 4c). We examine the Southern Ocean circulation changes and redistributive anomalies they cause. Comparing the Southern Ocean meridional overturning circulation in the $\mathrm{TS}_{\text {pert }}$ and $\mathrm{TSW}_{\text {pert }}$, we see a poleward shift in the streamlines of the Antarctic Circumpolar Current (ACC) and the southern edge of the subtropical cell (cf. color shading and contours in Fig. 9a). This poleward shift corresponds to the northward-flowing (positive) overturning anomalies centered around $60^{\circ} \mathrm{S}$ and the southward-flowing (negative) overturning circulation anomalies resulting from 

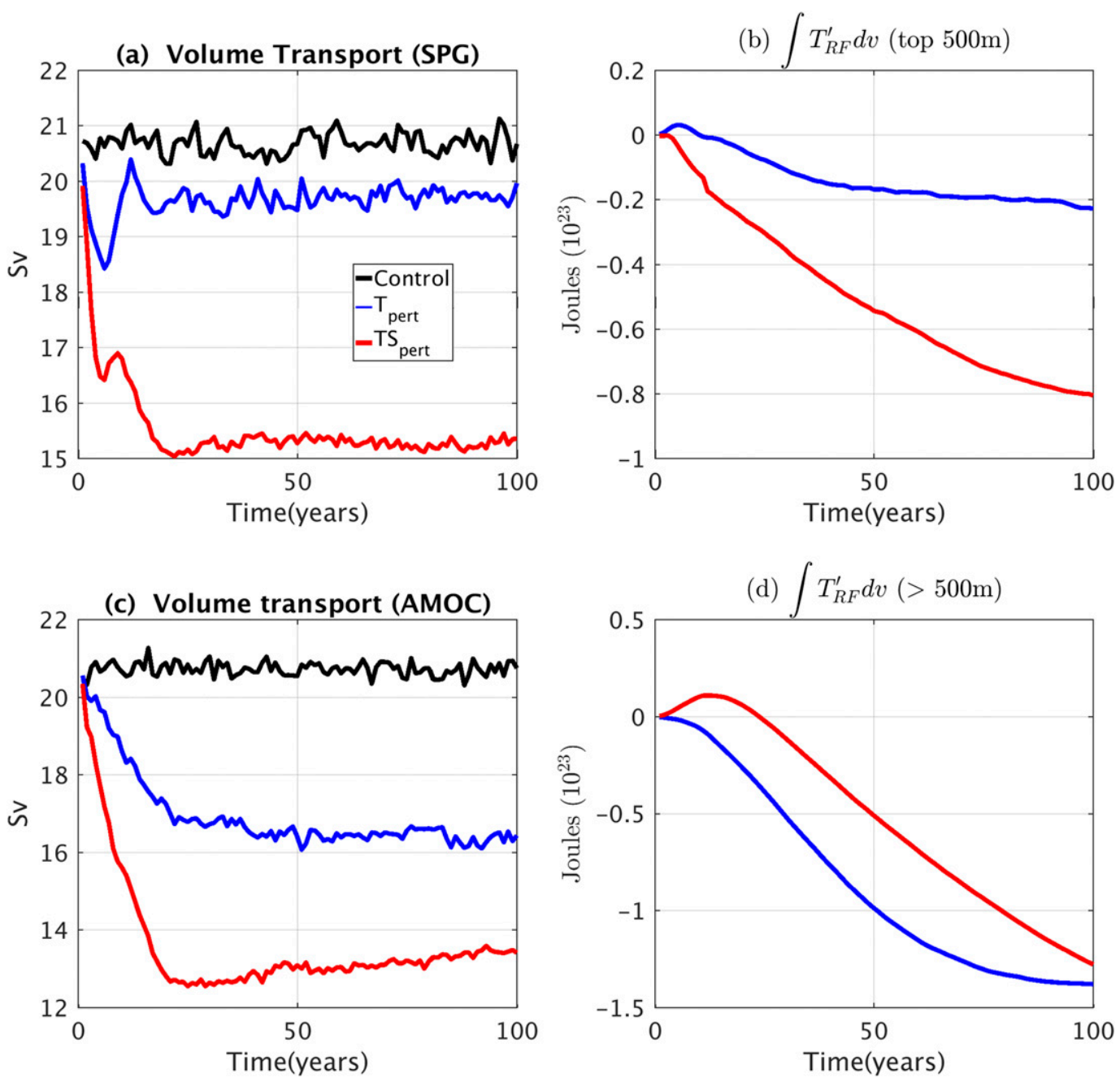

FIG. 8. (a) The North Atlantic volume transport in the SPG and (b) redistributive heat content anomaly in the top $500 \mathrm{~m}\left(40^{\circ}-80^{\circ} \mathrm{N}\right)$. (c) Volume transport in the AMOC and (d) redistributive heat content anomaly below $500 \mathrm{~m}$ $\left(40^{\circ}-80^{\circ} \mathrm{N}\right)$.

the wind perturbation in Fig. 9b. This wind-induced circulation change pattern seen here is also a robust feature of global warming experiments and historical trends (Mikolajewicz and Voss 2000; Saenko et al. 2005; Yang et al. 2016). These studies show that wind changes weaken the subtropical gyres and that there is a poleward shift of the southern subtropical gyre around $45^{\circ} \mathrm{S}$ in all the basins, and the ACC is also shifted poleward.

However, the volume transport weakening resulting from the wind perturbation is small. Defining the volume transport at the location of the meridional streamfunction maximum as the total volume transport by the circulation, the subtropical cells weaken only by about $3 \mathrm{~Sv}$ (Fig. 9b). The total subtropical cell transport in the $\mathrm{TS}_{\text {pert }}$ experiment is about $47 \mathrm{~Sv}$; therefore, wind perturbation weakens the subtropical cell volume transports by about
$5 \%$. The Southern Ocean volume transport also weakens only by about $1 \mathrm{~Sv}$ in the $\mathrm{TSW}_{\text {pert }}$ experiment; this is about $2 \%$ of the circulation strength $(41 \mathrm{~Sv})$ in the $\mathrm{TS}_{\text {pert }}$ experiment (Fig. 9a, contours). In fact, the temperatureinduced weakening of the subtropical cells seen in the $\mathrm{TS}_{\text {pert }}$ experiment in Fig. 9c is much larger, explaining the greater tropical active heat loss resulting from the temperature perturbation. Therefore, the wind-induced redistributive warming is caused mainly by the poleward shift of the circulation rather than its weakening.

To see the redistributive temperature anomalies that might be caused by this poleward shift, we look at the meridional velocity anomalies and the initial temperature gradient. The subtropical cell causes a net southward flow, while the ACC causes a net northward flow at the surface, which converge around $40^{\circ} \mathrm{S}$ in the 

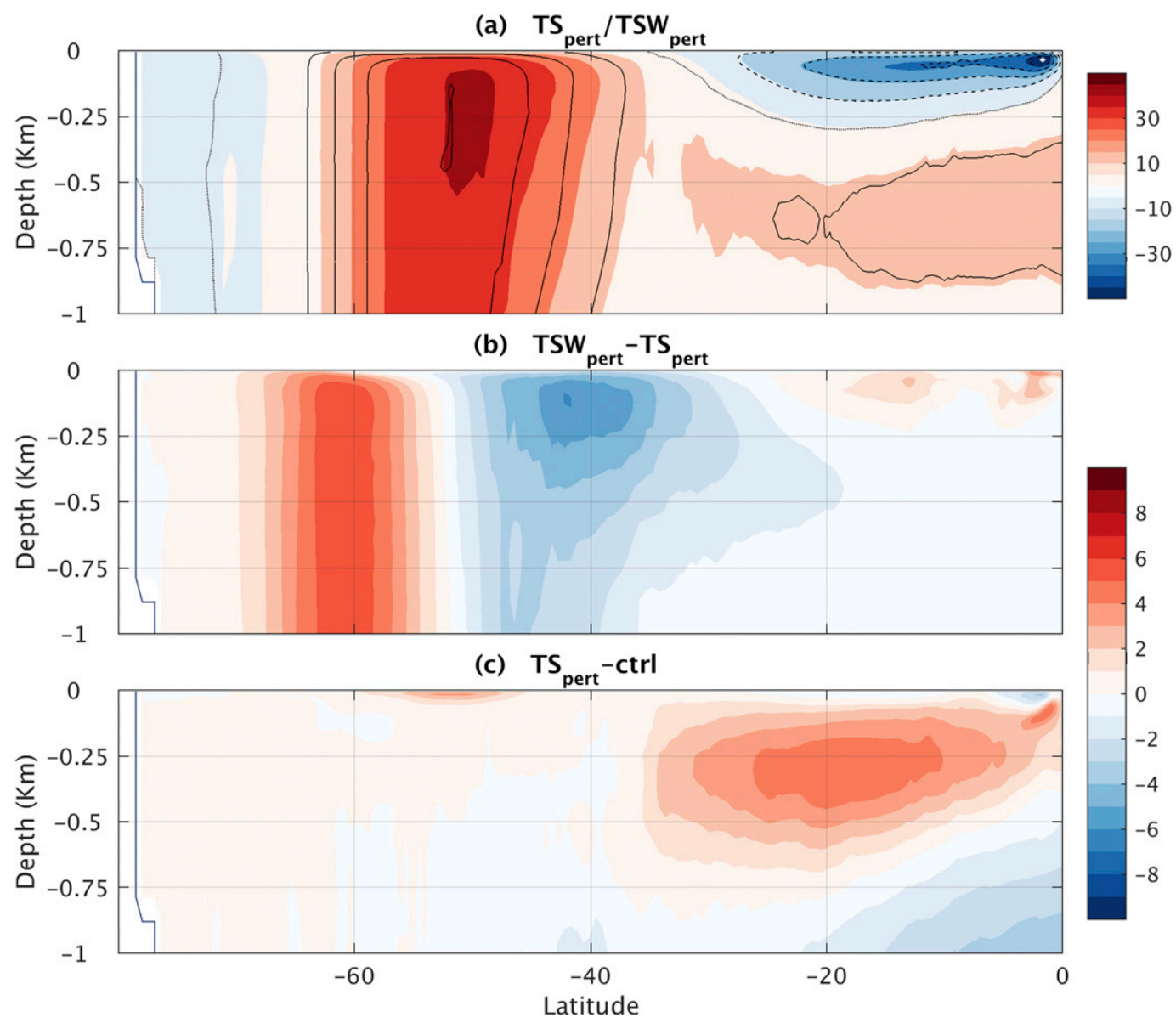

FIG. 9. (a) Global meridional overturning streamfunction in the $\mathrm{TS}_{\text {pert }}$ (color shading) experiment and the $\mathrm{TSW}_{\text {pert }}$ (contours, contour interval is $10 \mathrm{~Sv}$ ). (b) Global meridional streamfunction anomalies caused by wind perturbation $\left(\mathrm{TSW}_{\text {pert }}-\mathrm{TS}_{\text {pert }}\right)$ and (c) in the $\mathrm{TS}_{\text {pert }}$ experiment. All variables are for the 100-yr time average; northward flow (red shading and solid contours) and southward flow (blue shading and dashed contours).

control or background circulation. Therefore, the poleward shift of the subtropical cells causes a southwardflow anomaly right at the southern edge of the subtropical cell, and a northward-flow anomaly at the southern edge of the ACC (Fig. 10, top; shading). The southward-flow anomaly causes redistributive warming at the southern edge of the subtropical gyre, because they transport the warm tropical waters farther poleward (Fig. 10, bottom; shading). These redistributive anomalies are relatively stronger than what would be expected from the shallow and weak velocity anomalies; however, the strong control temperature gradient here causes relatively large redistributive anomalies (Fig. 10, top; contours). The redistributive anomalies are further transported away from the surface because of the sinking in the background circulation in this region (Fig. 10, bottom; contours). The weakened subtropical cells in the basins only cause modest redistributive warming anomalies in the tropical surface in the $\mathrm{TSW}_{\text {pert }}$ experiment.

\section{Summary and discussion}

Using a set of three sensitivity experiments, we isolate the roles of the $\mathrm{CO}_{2}$-induced surface fluxes of heat, freshwater, and momentum perturbations in ocean heat uptake through their individual contributions to the passive and active (redistribution feedback) heat uptake components. Surface heat flux perturbation is common to all the experiments, and directly causes the passive heat uptake, while each surface flux perturbation causes an active heat uptake through the changes they cause in the pattern and magnitude of ocean circulation. The passive component is not sensitive to the variation in the magnitude and pattern of circulation changes caused by each surface flux perturbation; however, the active component is very sensitive to these circulation changes, causing the large variation in the total ocean heat uptake among the experiments.

The passive uptake accounts for most (about 87\%) of the total heat uptake due to all the surface flux 

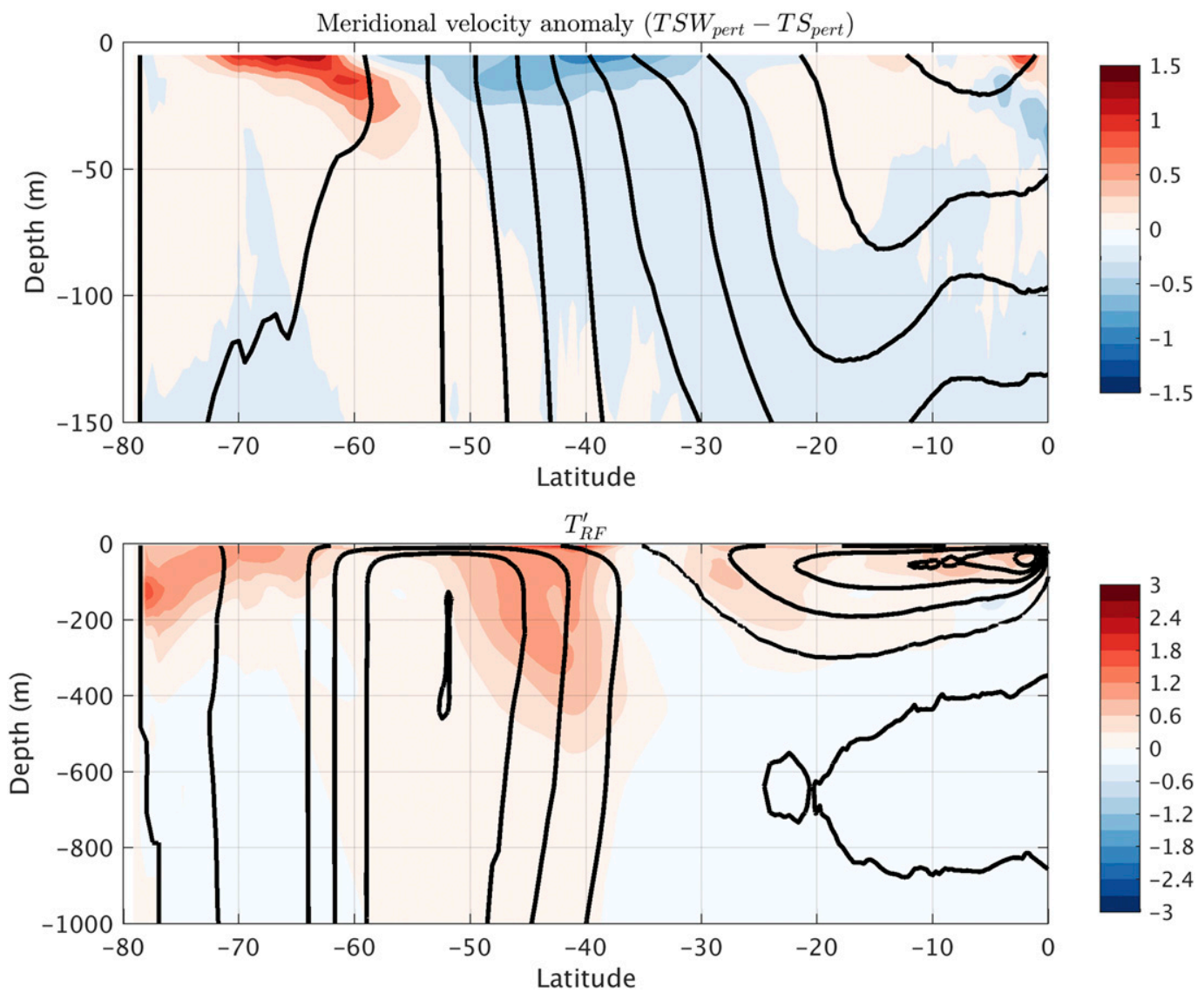

FIG. 10. Global zonally averaged (top) meridional velocity anomalies resulting from wind perturbation (color shading, interval $=0.25 \mathrm{~cm} \mathrm{~s}^{-1}$ ) and control temperature (contours, interval $=3^{\circ} \mathrm{C}$ ) and (bottom) redistributive temperature anomalies $T_{\mathrm{RF}}^{\prime}$ resulting from wind perturbation $\left(\mathrm{TSW}_{\text {pert }}-\mathrm{TS}_{\text {pert }}\right.$; color shading, interval $=0.3^{\circ} \mathrm{C}$ ) and meridional overturning circulation in the TSW experiment (contours, interval $=10 \mathrm{~Sv}$ ). All variables are for the 100-yr time average.

perturbations, while the net active heat uptake caused by all the surface flux perturbations accounts for $13 \%$ of the total heat uptake. Surface freshwater perturbations cause a large active heat gain, about $34 \%$ of the total heat uptake, largely because of the large surface cooling it causes in the subpolar Atlantic through the weakening of the subpolar gyre. Surface heat flux and wind perturbations each cause a net active heat loss of about $12 \%$ of the total uptake, cancelling out most of the active heat gain resulting from the freshwater perturbation. The active heat loss caused by surface heat flux perturbation occurs largely as a result of the surface warming in the tropical Pacific due to the weakening of the subtropical cells there, while that caused by wind perturbations is largely due to the surface warming around the edge of the subtropical cell, caused by the poleward shift of the southern subtropical cells.

One major result of this study is that the active heat uptake is not necessarily related to the degree of AMOC weakening as often suggested (Xie and Vallis 2012; Rugenstein et al. 2013; Kostov et al. 2014). Rather, it is more sensitive to shallow circulation changes in the basins, mainly in the Pacific subtropical gyre, Atlantic subpolar gyre, and the southern Atlantic subtropical gyre. Our results show that surface heat flux perturbations cause most of the AMOC weakening, a feature shown to be robust in global warming simulations, yet it results in a net global active heat loss because of the relatively weaker subpolar Atlantic cooling it causes in spite of the AMOC weakening. Surface freshwater perturbations, on the other hand, weaken the AMOC less, but cause a very large cooling of the subpolar Atlantic because they cause more weakening of the subpolar gyre than the AMOC.

These results have been implied in other studies; Drijfhout et al. (2012) showed that the robust cooling of the subpolar Atlantic (warming hole) in historical simulations may not be fully attributable to AMOC weakening. The global warming passive tracer experiments of Xie and Vallis (2012) and Marshall et al. (2015), forced with surface heat flux perturbations alone, also show a 
large AMOC weakening and yet a shallowing of the global average depth of heat uptake due to circulation changes. This shallowing of the depth of uptake implies a net redistributive surface warming and active heat loss by the ocean, and therefore is consistent with the active heat loss due to surface heat flux perturbations found here. As shown in Garuba and Klinger (2016), another impact of the heat redistribution by ocean circulation change is on the average depth of heat uptake; when redistribution warms the surface globally, it causes shallower penetration of heat, and vice versa. Similarly, Sévellec and Fedorov (2016) show that surface freshwater flux perturbations cause weaker northward heat transport within a century following global warming, even though they cause less volume transport weakening than surface heat flux perturbations. This result implies a larger polar cooling and active heat uptake by freshwater perturbations than surface heat flux perturbations, which is consistent with the results here.

Furthermore, our results are consistent with the model intercomparison study of Gregory et al. (2016) on the impact of surface flux perturbations on sea level rise. They found that on the model average, surface heat flux perturbations cause most of the AMOC weakening, yet freshwater flux perturbations cause most of the redistributive surface cooling. The global surface temperature changes resulting from surface heat flux, freshwater flux, and wind perturbations, are $-0.05,-0.32$, and $0.15 \mathrm{~K}$, respectively. These global redistributive surface temperature changes imply an active ocean heat uptake of the opposite sign, that is, redistributive surface cooling implies active heat gain and vice versa. A major difference in their experimental design is that they use the total fully coupled surface heat flux anomaly, which includes the active heat fluxes caused by all the surface flux perturbations, rather than the passive surface heat flux perturbation used here. Therefore, surface heat flux perturbations cause a small redistributive surface cooling in their study, instead of the redistributive surface warming here. Nevertheless, the greater global redistributive surface cooling caused by freshwater perturbations is consistent with our result of greater active heat input by freshwater perturbation than heat flux perturbations; similarly, the redistributive surface warming caused by wind changes is consistent with the active heat loss by wind perturbation here. These multimodel results suggest that the larger impact of the freshwater perturbations on the Atlantic active heat uptake, in spite of the smaller AMOC weakening they cause, might be robust.

As we show here, the subpolar Atlantic dominates the net global active uptake through the subpolar gyre changes, and buoyancy-forced subpolar gyre changes are tightly coupled to AMOC changes (Böning et al. 2006; Robson et al. 2012; Yeager and Danabasoglu 2014; Buckley and Marshall 2016). This might explain why the North Atlantic active uptake is often attributed to AMOC weakening. We speculate that the reason salinity and temperature forcing perturbations cause different patterns and magnitudes of subpolar redistributive cooling, although causing the same pattern of AMOC weakening, may be due to the distribution of these surface flux anomalies. Saenko et al. (2007) and Smith and Gregory (2009) have shown that the North Atlantic warming response is very sensitive to the distribution of surface freshwater flux anomalies. Freshening in the middle of the gyre around $55^{\circ} \mathrm{N}$ showed the most surface air temperature (SAT) cooling in the study of Smith and Gregory (2009).

Finally, one caveat of the approach here is the linear response assumption of our experimental design. Although the ocean circulation response to each surface flux perturbation is shown to be linear in the study of Mikolajewicz and Voss (2000), nonlinearities may be larger for our experiments because of the greater magnitude of the surface perturbations. We have also analyzed sensitivity experiments in one model; the ocean heat uptake sensitivity to surface flux perturbation will vary in other models. Despite these caveats, we note that the redistributive surface temperature anomaly patterns causing the active heat uptake in this study-the El Niño-like warming pattern of the tropical Pacific, the large cooling of the subpolar Atlantic (termed warming hole), and the warming in the South Atlantic, spanning the Brazil and Agulhas Currents-are all robust features of global warming simulations and historical warming trends. Therefore, the variation in these patterns and the surface heat fluxes associated with them will be useful in diagnosing global warming response and ocean heat uptake variation among models.

Acknowledgments. Work on this project was supported by NSF Grants 1249156 and 133842, and the U.S. Department of Energy Office of Science Biological and Environmental Research (BER) as part of the Regional and Global Climate Modeling Program. PNNL is operated for DOE by Battelle Memorial Institute under Contract DE-AC05-76RL0183DOE. We also acknowledge the high performance computing support from Yellowstone (http://n2t.net/ark:/85065/d7wd3xhc) provided by NCAR's Computational and Information Systems Laboratory, sponsored by the National Science Foundation. We also thank the three anonymous reviewers for their constructive reviews, and Bohua Huang, Jim Kinter, and Jian Lu for the helpful conversations.

\section{REFERENCES}

Andrews, T., J. M. Gregory, and M. J. Webb, 2015: The dependence of radiative forcing and feedback on evolving patterns of surface temperature change in climate models. J. Climate, 28, 16301648, https://doi.org/10.1175/JCLI-D-14-00545.1. 
Banks, H. T., and J. M. Gregory, 2006: Mechanisms of ocean heat uptake in a coupled climate model and the implications for tracer based predictions of ocean heat uptake. Geophys. Res. Lett., 33, L07608, https://doi.org/10.1029/2005GL025352.

Böning, C. W., M. Scheinert, J. Dengg, A. Biastoch, and A. Funk, 2006: Decadal variability of subpolar gyre transport and its reverberation in the North Atlantic overturning. Geophys. Res. Lett., 33, L21S01, https://doi.org/10.1029/2006GL026906.

Bouttes, N., J. M. Gregory, T. Kuhlbrodt, and R. S. Smith, 2014: The drivers of projected North Atlantic sea level change. Climate Dyn., 43, 1531-1544, https://doi.org/10.1007/s00382-013-1973-8.

Bryan, K., 1984: Accelerating the convergence to equilibrium of ocean-climate models. J. Phys. Oceanogr., 14, 666-673, https:// doi.org/10.1175/1520-0485(1984)014<0666:ATCTEO >2.0.CO;2.

Buckley, M. W., and J. Marshall, 2016: Observations, inferences, and mechanisms of the Atlantic meridional overturning circulation: A review. Rev. Geophys., 54, 5-63, https://doi.org/ 10.1002/2015RG000493.

Drijfhout, S., G. J. van Oldenborgh, and A. Cimatoribus, 2012: Is a decline of AMOC causing the warming hole above the North Atlantic in observed and modeled warming patterns? J. Climate, 25, 8373-8379, https://doi.org/10.1175/JCLI-D-12-00490.1.

Garuba, O. A., and B. A. Klinger, 2016: Ocean heat uptake and interbasin transport of the passive and redistributive components of surface heating. J. Climate, 29, 7507-7527, https:// doi.org/10.1175/JCLI-D-16-0138.1.

Gent, P. R., J. Willebrand, T. J. McDougall, and J. C. McWilliams, 1995: Parameterizing eddy-induced tracer transports in ocean circulation models. J. Phys. Oceanogr., 25, 463-474, https://doi.org/ 10.1175/1520-0485(1995)025<0463:PEITTI >2.0.CO;2.

_ , and Coauthors, 2011: The Community Climate System Model version 4. J. Climate, 24, 4973-4991, https://doi.org/ 10.1175/2011JCLI4083.1.

Gregory, J. M., and Coauthors, 2005: A model intercomparison of changes in the Atlantic thermohaline circulation in response to increasing atmospheric $\mathrm{CO}_{2}$ concentration. Geophys. Res. Lett., 32, L12703, https://doi.org/10.1029/2005GL023209.

_ , and Coauthors, 2016: The Flux-Anomaly-Forced Model Intercomparison Project (FAFMIP) contribution to CMIP6: Investigation of sea-level and ocean climate change in response to $\mathrm{CO}_{2}$ forcing. Geosci. Model Dev., 9, 3993-4017, https://doi.org/10.5194/gmd-9-3993-2016.

Huber, M. B., and L. Zanna, 2017: Drivers of uncertainty in simulated ocean circulation and heat uptake. Geophys. Res. Lett., 44, 1402-1413, https://doi.org/10.1002/2016GL071587.

Kostov, Y., K. C. Armour, and J. Marshall, 2014: Impact of the Atlantic meridional overturning circulation on ocean heat storage and transient climate change. Geophys. Res. Lett., 41, 2108-2116, https://doi.org/10.1002/2013GL058998.

Large, W. G., J. C. McWilliams, and S. C. Doney, 1994: Oceanic vertical mixing: A review and a model with a nonlocal boundary layer parameterization. Rev. Geophys., 32, 363-403, https://doi.org/10.1029/94RG01872.

Luo, Y., J. Lu, F. Liu, and W. Liu, 2015: Understanding the El Niño-like oceanic response in the tropical Pacific to global warming. Climate Dyn., 45, 1945-1964, https://doi.org/10.1007/ s00382-014-2448-2.

_ — _ - _ and O. Garuba, 2017: The role of ocean dynamical thermostat in delaying the El Niño-like response over the equatorial Pacific to climate warming. J. Climate, 30, 28112827, https://doi.org/10.1175/JCLI-D-16-0454.1.
Marshall, J., J. R. Scott, K. C. Armour, J.-M. Campin, M. Kelley, and A. Romanou, 2015: The ocean's role in the transient response of climate to abrupt greenhouse gas forcing. Climate Dyn., 44, 2287-2299, https://doi.org/10.1007/s00382-014-2308-0.

Mikolajewicz, U., and R. Voss, 2000: The role of the individual airsea flux components in $\mathrm{CO}_{2}$-induced changes of the ocean's circulation and climate. Climate Dyn., 16, 627-642, https:// doi.org/10.1007/s003820000066.

Robson, J., R. Sutton, K. Lohmann, D. Smith, and M. D. Palmer, 2012: Causes of the rapid warming of the North Atlantic Ocean in the mid-1990s. J. Climate, 25, 4116-4134, https:// doi.org/10.1175/JCLI-D-11-00443.1.

Rugenstein, M. A. A., M. Winton, R. J. Stouffer, S. M. Griffies, and R. Hallberg, 2013: Northern high-latitude heat budget decomposition and transient warming. J. Climate, 26, 609-621, https://doi.org/10.1175/JCLI-D-11-00695.1.

Saenko, O. A., J. C. Fyfe, and M. H. England, 2005: On the response of the oceanic wind-driven circulation to atmospheric $\mathrm{CO}_{2}$ increase. Climate Dyn., 25, 415-426, https://doi.org/ 10.1007/s00382-005-0032-5.

, A. J. Weaver, D. Y. Robitaille, and G. M. Flato, 2007: Warming of the subpolar Atlantic triggered by freshwater discharge at the continental boundary. Geophys. Res. Lett., 34, L15604, https://doi.org/10.1029/2007GL030674.

Sévellec, F., and A. V. Fedorov, 2016: AMOC sensitivity to surface buoyancy fluxes: Stronger ocean meridional heat transport with a weaker volume transport? Climate Dyn., 47, 1497-1513, https://doi.org/10.1007/s00382-015-2915-4.

- - , and W. Liu, 2017: Arctic sea-ice decline weakens the Atlantic meridional overturning circulation. Nat. Climate Change, 7, 604-610, https://doi.org/10.1038/nclimate3353.

Smith, R. D., and P. Gent, Eds., 2002: Reference manual for the Parallel Ocean Program (POP): Ocean component of the Community Climate System Model (CCSM2.0 and 3.0). Los Alamos National Laboratory Tech. Rep. LAUR-02-2484, 76 pp., http://www.cesm.ucar.edu/models/ccsm3.0/pop/doc/manual.pdf.

Smith, R. S., and J. M. Gregory, 2009: A study of the sensitivity of ocean overturning circulation and climate to freshwater input in different regions of the North Atlantic. Geophys. Res. Lett., 36, L15701, https://doi.org/10.1029/2009GL038607.

—, R. Sutton, and J. M. Gregory, 2014: The impact of salinity perturbations on the future uptake of heat by the Atlantic Ocean. Geophys. Res. Lett., 41, 9072-9079, https://doi.org/ 10.1002/2014GL062169.

Taylor, K. E., R. J. Stouffer, and G. A. Meehl, 2012: An overview of CMIP5 and the experiment design. Bull. Amer. Meteor. Soc., 93, 485-498, https://doi.org/10.1175/BAMS-D-11-00094.1.

Weaver, A. J., M. Eby, M. Kienast, and O. A. Saenko, 2007: Response of the Atlantic meridional overturning circulation to increasing atmospheric $\mathrm{CO}_{2}$ : Sensitivity to mean climate state. Geophys. Res. Lett., 34, L05708, https://doi.org/10.1029/2006GL028756.

Xie, P., and G. K. Vallis, 2012: The passive and active nature of ocean heat uptake in idealized climate change experiments. Climate Dyn., 38, 667-684, https://doi.org/10.1007/s00382-011-1063-8.

Yang, H., G. Lohmann, W. Wei, M. Dima, M. Ionita, and J. Liu, 2016: Intensification and poleward shift of subtropical western boundary currents in a warming climate. J. Geophys. Res. Oceans, 121, 4928-4945, https://doi.org/10.1002/2015JC011513.

Yeager, S., and G. Danabasoglu, 2014: The origins of latetwentieth-century variations in the large-scale North Atlantic circulation. J. Climate, 27, 3222-3247, https://doi.org/10.1175/ JCLI-D-13-00125.1. 